\title{
A Systematic Review of the Potential Chemoprotective Effects of Resveratrol on Doxorubicin-Induced Cardiotoxicity: Focus on the Antioxidant, Antiapoptotic, and Anti-Inflammatory Activities
}

\author{
Li-Feng Hu $\mathbb{D}^{1},{ }^{1}$ Huan-Rong Lan $\mathbb{D}^{2},{ }^{2}$ Xue-Min Li $\mathbb{D}^{3},{ }^{3}$ and Ke-Tao Jin $\mathbb{D}^{4}$ \\ ${ }^{1}$ Department of Colorectal Surgery, Shaoxing People's Hospital (Shaoxing Hospital, Zhejiang University School of Medicine), \\ Shaoxing, Zhejiang 312000, China \\ ${ }^{2}$ Department of Breast and Thyroid Surgery, Affiliated Jinhua Hospital, Zhejiang University School of Medicine, Jinhua, \\ 321000 Zhejiang Province, China \\ ${ }^{3}$ Department of Hepatobiliary Surgery, Affiliated Jinhua Hospital, Zhejiang University School of Medicine, Jinhua, \\ 321000 Zhejiang Province, China \\ ${ }^{4}$ Department of Colorectal Surgery, Affiliated Jinhua Hospital, Zhejiang University School of Medicine, Jinhua, \\ 321000 Zhejiang Province, China
}

Correspondence should be addressed to Xue-Min Li; 1xm2100236@163.com and Ke-Tao Jin; jinketao2001@zju.edu.cn

Received 13 June 2021; Accepted 8 August 2021; Published 23 August 2021

Academic Editor: H. P. Vasantha Rupasinghe

Copyright (C) $2021 \mathrm{Li}$-Feng Hu et al. This is an open access article distributed under the Creative Commons Attribution License, which permits unrestricted use, distribution, and reproduction in any medium, provided the original work is properly cited.

Purpose. Although doxorubicin chemotherapeutic drug is commonly used to treat various solid and hematological tumors, its clinical use is restricted because of its adverse effects on the normal cells/tissues, especially cardiotoxicity. The use of resveratrol may mitigate the doxorubicin-induced cardiotoxic effects. For this aim, we systematically reviewed the potential chemoprotective effects of resveratrol against the doxorubicin-induced cardiotoxicity. Methods. In the current study, a systematic search was performed based on Preferred Reporting Items for Systematic Reviews and Meta-Analyses (PRISMA) guideline for the identification of all relevant studies on "the role of resveratrol on doxorubicin-induced cardiotoxicity" in the electronic databases of Web of Science, PubMed, and Scopus up to March 2021 using search terms in their titles and abstracts. Two hundred and eighteen articles were screened in accordance with a predefined set of inclusion and exclusion criteria. Finally, 33 eligible articles were included in this systematic review. Results. The in vitro and in vivo findings demonstrated a decreased cell survival, increased mortality, decreased heart weight, and increased ascites in the doxorubicin-treated groups compared to the control groups. The combined treatment of resveratrol and doxorubicin showed an opposite pattern than the doxorubicin-treated groups alone. Furthermore, this chemotherapeutic agent induced the biochemical and histopathological changes on the cardiac cells/tissue; however, the results (for most of the cases) revealed that these alterations induced by doxorubicin were reversed near to normal levels (control groups) by resveratrol coadministration. Conclusion. The results of this systematic review stated that coadministration of resveratrol alleviates the doxorubicin-induced cardiotoxicity. Resveratrol exerts these chemoprotective effects through several main mechanisms of antioxidant, antiapoptosis, and anti-inflammatory.

\section{Introduction}

Cancer, the uncontrolled growth of cells, is the second leading cause of death in the world [1-3], and also, its incidence and mortality are rapidly growing [4]. According to a recent report, an estimated 19.3 million new cancer cases and almost 10.0 million cancer deaths happened worldwide in 2020 [5]. The conventional modalities for cancer treatment are surgery, chemotherapy, and radiotherapy [6-9]. Although chemotherapy is effectively used for systemic treatment of different cancers, it suffers from several restrictions, such as nonspecificity and various adverse effects on 
normal cells and tissues; hence, its clinical utility is limited $[10,11]$.

Doxorubicin (Adriamycin) belongs to the anthracycline class medication which is commonly applied since the late 1960s for treatment of various tumors, including Hodgkin lymphoma, non-Hodgkin lymphoma, breast cancer, lung cancer, testicular cancer, thyroid cancer, and ovarian cancer [12-14]. Some immediate side effects have been reported for this chemotherapeutic drug, which are reversible or clinically manageable, such as arrhythmia, myelosuppression, vomiting, and nausea [13]. However, doxorubicin-induced cardiotoxicity is a serious adverse effect and can reduce quality of life and sometimes fatalities, leading to restriction of the clinical use of this chemotherapy drug [15]. In this regard, the use of chemoprotective agents during doxorubicin treatment has been suggested which may mitigate the adverse effects and improve patient survival.

According to the published studies, it can be mentioned that using the herbal and natural products or their derivatives to alleviate the chemotherapy-induced adverse effects (chemoprotectors) or increase the sensitivity of cancer cells to chemotherapy drugs (chemo/radiosensitizers) has attracted much attention over the past several decades. Resveratrol (3,5,4' ${ }^{\prime}$-trihydroxy-trans-stilbene, Figure 1), as a natural polyphenol, is found in more than 70 plant species. The main sources reported for this herbal agent are grapes, red wine, soy, and peanuts [16-19]. Naturally, resveratrol can protect the herbs against fungal, ultraviolet rays, and other stresses [20]. Moreover, it is reported that this herbal agent has potent antioxidant and anticlastogenic activities, helping to protect against genomic instability and carcinogenesis [21, 22]. Resveratrol also has some abilities to kill tumoral cells and sensitize tumor cells to therapeutic modalities such as chemotherapy and radiotherapy [21], as its anticancer activity has been assessed in many tumor types, such as colorectal cancer, prostate cancer, lung cancer, liver cancer, and breast cancer [23-26]. Additionally, it has been shown that resveratrol not only acts as a chemosensitizer agent but also has chemopreventive activities which are linked to its antiproliferative, antioxidant, antiapoptosis, and anti-inflammatory activities $[27,28]$. Other biological activities of resveratrol such as neuroprotective, radioprotective, and cardioprotective properties have also been reported [19, 29]. It has also recently been reported that resveratrol can be effective in the management of acute pancreatitis [30].

To the best of our knowledge, this study is the first systematic review on the cardioprotective role of resveratrol, as an adjuvant, during doxorubicin treatment. Additionally, it was tried to discuss the following questions. (1) How does doxorubicin chemotherapeutic agent lead to cardiotoxicity? (2) What are the underlying mechanisms of doxorubicininduced cardiotoxicity? (3) What is the role of resveratrol on the doxorubicin-induced cardiotoxicity? (4) What are the cardioprotective mechanisms of resveratrol against doxorubicin-induced cardiotoxicity?

\section{Methods}

The present systematic review was performed based on the Preferred Reporting Items for Systematic Reviews and

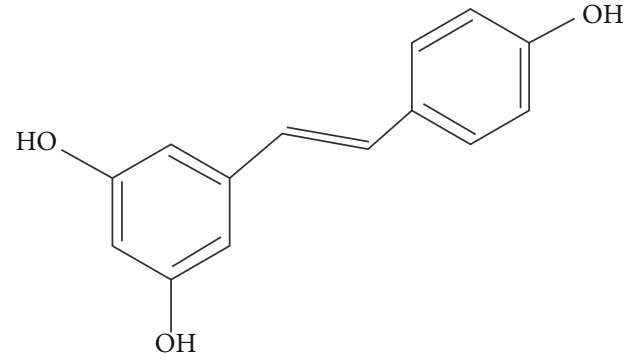

FIgURE 1: Chemical structure of resveratrol.

Meta-Analyses (PRISMA) guidelines [31] (see Table 1). A PICO framework was also applied to structure the review process [31] that was composed of participants (P): doxorubicin-damaged cardiac cells (in vitro studies) and/or patients/animals with doxorubicin-induced cardiotoxicity (clinical/in vivo studies); intervention (I): chemotherapies with doxorubicin-based regimens; comparison (C): patients/animals/cells treated with resveratrol and doxorubicin; and outcomes $(\mathrm{O})$ : we selected two critical outcomes as follows: (i) changes in the cardiac cells/tissue following doxorubicin administration compared to control or untreated groups and (ii) changes in the cardiac cells/tissue following combined treatment of resveratrol and doxorubicin compared to doxorubicin treatment alone. Of note, the review protocol was not registered.

2.1. Search Strategy. A comprehensive systematic search was performed to obtain all relevant studies on "the role of resveratrol on doxorubicin-induced cardiotoxicity" in both medical subject heading $(\mathrm{MeSH})$ or advance in the electronic databases of Web of Science, PubMed, and Scopus up to Mach 2021 using the keywords "Resveratrol" AND "Doxorubicin" OR "Adriamycin" AND "Heart" OR "myocardium" OR "Myocardial” OR "Cardiac Toxicity” OR "Cardiac Toxicities" "Cardiomyopathy" OR "Myocyte" OR "Cardiopathic" OR "Cardiopathy" OR "cardiotoxicity" OR "Cardiotoxicities" OR "Cardiomyocyte" OR "Arrhythmias" OR “Cardiac” in title, abstract, or keywords.

2.2. Study Selection Process. The inclusion criteria considered in the current study were full-text articles with (a) English language, (b) our per-defined purpose on the role of resveratrol on doxorubicin-induced cardiotoxicity (based on the aforementioned keywords), (c) adequate data, (d) no restriction in publications with clinical, in vivo, or in vitro studies, and (e) no restriction on publication year. The exclusion criteria considered for this study were (a) hemodynamic data, (b) not related studies, (c) review articles, (d) case reports, (e) editorials, (f) letters to the editors, (g) oral presentations, (h) posters, and (i) book chapters.

2.3. Data Extraction Process. Each eligible study was assessed by two researchers and the following information were then extracted: (1) author name and year of publication, (2) models (clinical, in vivo, or/and in vitro), (3) doxorubicin dosage, protocol of usage, and type of 
TABLe 1: PRISMA checklist [31].

\begin{tabular}{|c|c|c|c|}
\hline Section/topic & $\#$ & Checklist item & $\begin{array}{l}\text { Reported on } \\
\text { page \# }\end{array}$ \\
\hline \multicolumn{4}{|l|}{ Title } \\
\hline Title & 1 & Identify the report as a systematic review, meta-analysis, or both. & 1 \\
\hline \multicolumn{4}{|l|}{ Abstract } \\
\hline Structured summary & 2 & $\begin{array}{l}\text { Provide a structured summary including, as applicable, background; objectives; data sources; } \\
\text { study eligibility criteria, participants, and interventions; study appraisal and synthesis methods; } \\
\text { results; limitations; conclusions and implications of key findings; systematic review registration } \\
\text { number. }\end{array}$ & 2 \\
\hline \multicolumn{4}{|l|}{ Introduction } \\
\hline Rationale & 3 & Describe the rationale for the review in the context of what is already known. & 3 and 4 \\
\hline Objectives & 4 & $\begin{array}{c}\text { Provide an explicit statement of questions being addressed with reference to participants, } \\
\text { interventions, comparisons, outcomes, and study design (PICOS). }\end{array}$ & 4 \\
\hline \multicolumn{4}{|l|}{ Methods } \\
\hline $\begin{array}{l}\text { Protocol and } \\
\text { registration }\end{array}$ & 5 & $\begin{array}{l}\text { Indicate if a review protocol exists, if and where it can be accessed (e.g., Web address), and, if } \\
\text { available, provide registration information including registration number. }\end{array}$ & N/A \\
\hline Eligibility criteria & 6 & $\begin{array}{c}\text { Specify study characteristics (e.g., PICOS and length of follow-up) and report characteristics } \\
\text { (e.g., years considered, language, and publication status) used as criteria for eligibility, giving } \\
\text { rationale. }\end{array}$ & 5 and 6 \\
\hline Information sources & 7 & $\begin{array}{l}\text { Describe all information sources (e.g., databases with dates of coverage and contact with study } \\
\text { authors to identify additional studies) in the search and date last searched. }\end{array}$ & 5 \\
\hline Search & 8 & $\begin{array}{l}\text { Present full electronic search strategy for at least one database, including any limits used, such } \\
\text { that it could be repeated. }\end{array}$ & 5 \\
\hline Study selection & 9 & $\begin{array}{l}\text { State the process for selecting studies (i.e., screening, eligibility, included in systematic review, } \\
\text { and, if applicable, included in the meta-analysis). }\end{array}$ & 6 \\
\hline $\begin{array}{l}\text { Data collection } \\
\text { process }\end{array}$ & 10 & $\begin{array}{l}\text { Describe method of data extraction from reports (e.g., piloted forms, independently, in } \\
\text { duplicate) and any processes for obtaining and confirming data from investigators. }\end{array}$ & 6 \\
\hline Data items & 11 & $\begin{array}{l}\text { List and define all variables for which data were sought (e.g., PICOS and funding sources) and } \\
\text { any assumptions and simplifications made. }\end{array}$ & 6 \\
\hline $\begin{array}{l}\text { Risk of bias in } \\
\text { individual studies }\end{array}$ & 12 & $\begin{array}{l}\text { Describe methods used for assessing risk of bias of individual studies (including specification of } \\
\text { whether this was done at the study or outcome level) and how this information is to be used in } \\
\text { any data synthesis. }\end{array}$ & N/A \\
\hline Summary measures & 13 & State the principal summary measures (e.g., risk ratio and difference in means). & $\mathrm{N} / \mathrm{A}$ \\
\hline Synthesis of results & 14 & $\begin{array}{l}\text { Describe the methods of handling data and combining results of studies, if done, including } \\
\left.\text { measures of consistency (e.g., } I^{2}\right) \text { for each meta-analysis. }\end{array}$ & N/A \\
\hline $\begin{array}{l}\text { Risk of bias across } \\
\text { studies }\end{array}$ & 15 & $\begin{array}{l}\text { Specify any assessment of risk of bias that may affect the cumulative evidence (e.g., publication } \\
\text { bias and selective reporting within studies). }\end{array}$ & $\mathrm{N} / \mathrm{A}$ \\
\hline Additional analyses & 16 & $\begin{array}{l}\text { Describe methods of additional analyses (e.g., sensitivity or subgroup analyses and } \\
\text { metaregression), if done, indicating which were prespecified. }\end{array}$ & $\mathrm{N} / \mathrm{A}$ \\
\hline \multicolumn{4}{|l|}{ Results } \\
\hline Study selection & 17 & $\begin{array}{l}\text { Give numbers of studies screened, assessed for eligibility, and included in the review, with } \\
\text { reasons for exclusions at each stage, ideally with a flow diagram. }\end{array}$ & $\begin{array}{c}\text { 6-7 } \\
\text { Figure } 1\end{array}$ \\
\hline Study characteristics & 18 & $\begin{array}{l}\text { For each study, present characteristics for which data were extracted (e.g., study size, PICOS, } \\
\text { and follow-up period) and provide the citations. }\end{array}$ & $\begin{array}{c}7-10 \\
\text { Table } 2\end{array}$ \\
\hline $\begin{array}{l}\text { Risk of bias within } \\
\text { studies }\end{array}$ & 19 & $\begin{array}{l}\text { Present data on risk of bias of each study and, if available, any outcome level assessment (see } \\
\text { item 12). }\end{array}$ & N/A \\
\hline $\begin{array}{l}\text { Results of individual } \\
\text { studies }\end{array}$ & 20 & $\begin{array}{c}\text { For all outcomes considered (benefits or harms), present for each study (a) simple summary } \\
\text { data for each intervention group and (b) effect estimates and confidence intervals, ideally with a } \\
\text { forest plot. }\end{array}$ & $\begin{array}{c}7-10 \\
\text { Table } 2\end{array}$ \\
\hline Synthesis of results & 21 & $\begin{array}{l}\text { Present results of each meta-analysis done, including confidence intervals and measures of } \\
\text { consistency. }\end{array}$ & N/A \\
\hline $\begin{array}{l}\text { Risk of bias across } \\
\text { studies }\end{array}$ & 22 & Present results of any assessment of risk of bias across studies (see item 15). & N/A \\
\hline Additional analysis & 23 & & N/A \\
\hline
\end{tabular}


TABle 1: Continued.

\begin{tabular}{|c|c|c|c|}
\hline Section/topic & $\#$ & Checklist item & $\begin{array}{l}\text { Reported on } \\
\text { page \# }\end{array}$ \\
\hline & & $\begin{array}{c}\text { Give results of additional analyses, if done (e.g., sensitivity or subgroup analyses and } \\
\text { metaregression (see item 16)). }\end{array}$ & \\
\hline \multicolumn{4}{|l|}{ Discussion } \\
\hline Summary of evidence & 24 & $\begin{array}{l}\text { Summarize the main findings including the strength of evidence for each main outcome; } \\
\text { consider their relevance to key groups (e.g., healthcare providers, users, and policy makers). }\end{array}$ & $10-16$ \\
\hline Limitations & 25 & $\begin{array}{l}\text { Discuss limitations at study and outcome level (e.g., risk of bias) and at review level (e.g., } \\
\text { incomplete retrieval of identified research and reporting bias). }\end{array}$ & 16 \\
\hline Conclusions & 26 & $\begin{array}{l}\text { Provide a general interpretation of the results in the context of other evidence and implications } \\
\text { for future research. }\end{array}$ & 16 \\
\hline \multicolumn{4}{|l|}{ Funding } \\
\hline Funding & 27 & $\begin{array}{l}\text { Describe sources of funding for the systematic review and other support (e.g., supply of data); } \\
\text { role of funders for the systematic review. }\end{array}$ & 17 \\
\hline
\end{tabular}

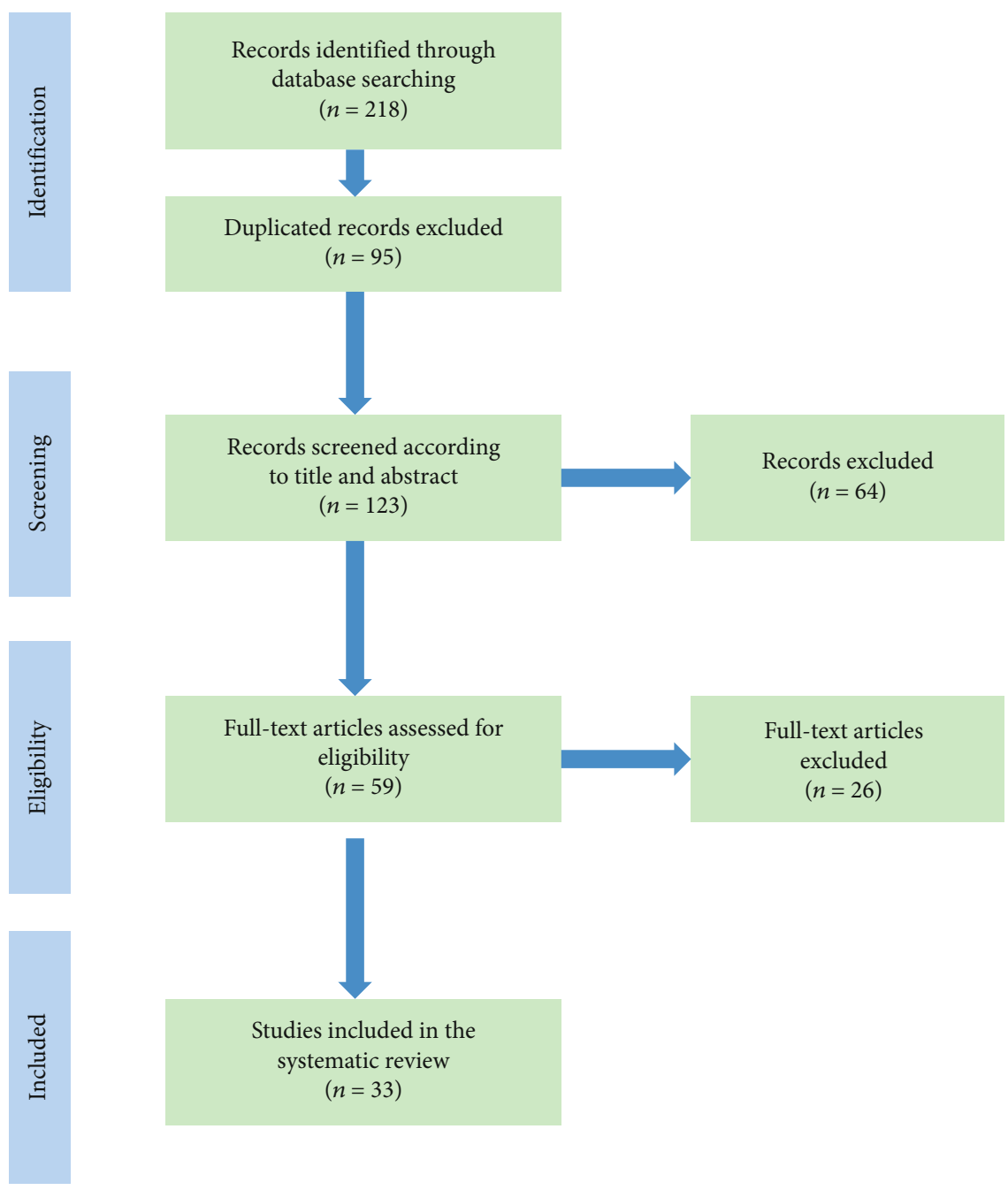

FIGURE 2: Flow diagram of PRISMA used in the present systematic review for selection process.

administration route, (4) outcomes of doxorubicin on cardiac cells/tissue, (5) resveratrol dosage, protocol of usage, and type of administration route, and (6) resveratrol coadministration outcomes.

\section{Results}

3.1. Literature Search and Screening. In Figure 2, the process of study selection is shown. 
TABLE 2: The characteristics of included studies.

\begin{tabular}{|c|c|c|c|c|c|}
\hline Model & $\begin{array}{l}\text { DOX dosage \& protocol } \\
\text { of usage; administration } \\
\text { route }\end{array}$ & $\begin{array}{l}\text { Outcomes of DOX on } \\
\text { cardiac cells/tissue }\end{array}$ & $\begin{array}{l}\text { Resveratrol dosage \& } \\
\text { protocol of usage; } \\
\text { administration route }\end{array}$ & $\begin{array}{c}\text { Resveratrol } \\
\text { coadministration } \\
\text { outcomes }\end{array}$ & $\begin{array}{l}\text { Author \& } \\
\text { year }\end{array}$ \\
\hline $\begin{array}{l}\text { In vitro/H9c2 } \\
\text { cells }\end{array}$ & $\begin{array}{c}5,10,20,30, \text { and } 40 \mu \mathrm{M} \\
\& 24 \mathrm{~h}\end{array}$ & $\downarrow$ Cell viability & $\begin{array}{l}100 \mu \mathrm{M} \& 72 \mathrm{~h} \text { prior to } \\
\text { DOX treatment }\end{array}$ & $\uparrow$ Cell viability & $\begin{array}{l}\text { Cao and } \mathrm{Li}, \\
2004[32]\end{array}$ \\
\hline $\begin{array}{l}\text { In vitro/neonatal } \\
\text { rat ventricular } \\
\text { myocytes }\end{array}$ & $10 \mu \mathrm{mol} / \mathrm{L} \& 48 \mathrm{~h}$ & $\downarrow$ Cell viability & $1 \mu \mathrm{mol} / \mathrm{L} \&$ cotreatment & $\uparrow$ Cell viability & $\begin{array}{l}\text { Rezk et al., } \\
2006[33]\end{array}$ \\
\hline $\begin{array}{l}\text { In vitro/H9c2 } \\
\text { cells }\end{array}$ & $20 \mu \mathrm{mol} / \mathrm{L} \& 4 \mathrm{~h}$ & $\downarrow$ Cell viability & $\begin{array}{c}5,10,20 \text {, and } 40 \mu \mathrm{M} \& \\
24 \mathrm{~h} \text { prior to DOX } \\
\text { treatment }\end{array}$ & $\uparrow$ Cell viability & $\begin{array}{l}\text { Yu et al., } \\
2007[34]\end{array}$ \\
\hline $\begin{array}{l}\text { In vitro/neonatal } \\
\text { rat ventricular } \\
\text { myocytes }\end{array}$ & $\begin{array}{c}1 \text { and } 50 \mu \mathrm{M} \& 10 \mathrm{~min} \\
\text { and } 24 \mathrm{~h}\end{array}$ & $\begin{array}{c}\uparrow \mathrm{ROS}, \downarrow \text { mitochondrial } \\
\text { activity, } \uparrow \text { cell death, } \downarrow \text { JC- } \\
1 \text { ratio (JC-1 aggregate/ } \\
\text { monomer), } \downarrow \text { SIRT1 } \\
\text { activity ( } \uparrow \text { acetylated } \\
\text { histone H3) }\end{array}$ & $\begin{array}{l}10 \mu \mathrm{M} \& 72 \mathrm{~h} \text { prior to } \\
\text { DOX treatment }\end{array}$ & $\begin{array}{c}\downarrow \text { ROS, } \uparrow \text { mitochondrial } \\
\text { activity, } \downarrow \text { cell death, } \downarrow \text { JC- } \\
1 \text { ratio (JC- } 1 \text { aggregate/ } \\
\text { monomer), } \uparrow \text { MnSOD, } \\
\uparrow \text { SIRT1 activity } \\
\text { ( } \downarrow \text { acetylated histone H3) }\end{array}$ & $\begin{array}{l}\text { Danz et al., } \\
2009 \text { [35] }\end{array}$ \\
\hline In vivo/rats & $\begin{array}{l}\text { Cumulative dose of } 20 \\
\mathrm{mg} / \mathrm{kg} \text { \& for a } 2 \text {-week } \\
\text { period; i.p. }\end{array}$ & $\begin{array}{c}\downarrow \text { Body weight and heart } \\
\text { weight, } \uparrow \text { plasma LDH } \\
\text { activity, } \uparrow \mathrm{CPK} \text { and AST } \\
\text { levels, } \uparrow \text { total cholesterol } \\
\text { and triglyceride levels, } \\
\downarrow \text { total antioxidant } \\
\text { capacity, } \uparrow 8 \text {-OHdG } \\
\text { level, } \uparrow \text { luminol and } \\
\text { lucigenin } \\
\text { chemiluminescence } \\
\text { levels, } \uparrow \mathrm{MDA}, \downarrow \mathrm{GSH}, \\
\downarrow \text { SOD and catalase } \\
\text { activities, } \uparrow \mathrm{MPO}, \downarrow \mathrm{Na}{ }^{+}, \\
\mathrm{K}^{+} \text {-ATPase activity, } \\
\uparrow \text { collagen content, } \\
\text { congestion, and } \\
\text { vacuolization in the } \\
\text { cytoplasm of the } \\
\text { cardiomyocytes }\end{array}$ & $\begin{array}{c}10 \mathrm{mg} / \mathrm{kg} / \mathrm{day} \& \text { for } 7 \\
\text { weeks (starting } 2 \text { weeks } \\
\text { prior to DOX } \\
\text { treatment); i.p. }\end{array}$ & $\begin{array}{c}\uparrow \text { Body weight and heart } \\
\text { weight, } \downarrow \text { plasma LDH } \\
\text { activity, } \downarrow \text { CPK and AST } \\
\text { levels, } \downarrow \text { total cholesterol } \\
\text { and triglyceride levels, } \\
\uparrow \text { total antioxidant } \\
\text { capacity, } \downarrow \text {-OHdG } \\
\text { levels, } \downarrow \text { luminol and } \\
\text { lucigenin } \\
\text { chemiluminescence } \\
\text { levels, } \uparrow \text { luminol and } \\
\text { lucigenin } \\
\text { chemiluminescence } \\
\text { levels, } \downarrow \text { MDA, } \uparrow G S H, \\
\uparrow S O D \text { and catalase } \\
\text { activities, } \downarrow \text { MPO, } \uparrow N a \\
\mathrm{~K}^{+} \text {-ATPase activity, } \\
\downarrow \text { collagen content, } \\
\downarrow \text { capillary } \\
\text { vasocongestion, } \\
\downarrow \text { vacuolization in the } \\
\text { cytoplasm of the cells, } \\
\text { regular cellular } \\
\text { morphology }\end{array}$ & $\begin{array}{c}\text { Tatlidede } \\
\text { et al., 2009 } \\
{[46]}\end{array}$ \\
\hline In vivo/rats & $\begin{array}{c}4 \mathrm{mg} / \mathrm{kg} / \text { day } \& \text { for } 1 \\
\text { week; i.p. }\end{array}$ & $\begin{array}{c}\uparrow \text { Creatine kinase, } \downarrow \text { LDH, } \\
\uparrow \text { total cholesterol, } \\
\uparrow \text { triglycerides, } \downarrow \text { GSH, } \\
\text { GPx, SOD, and catalase } \\
\text { activities, } \uparrow \text { TBARS, } \\
\uparrow \text { edema }\end{array}$ & $\begin{array}{c}4 \text { and } 8 \mathrm{mg} / \mathrm{kg} / \text { day } \& \text { for } \\
2 \text { weeks (starting } 1 \text { week } \\
\text { prior to DOX } \\
\text { administration); enteral }\end{array}$ & $\begin{array}{c}\uparrow \mathrm{LDH}, \downarrow \text { total } \\
\text { cholesterol, } \\
\downarrow \text { triglycerides, } \uparrow \mathrm{GSH}, \\
\text { GPx, SOD, and catalase } \\
\text { activities, } \downarrow \text { TBARS, } \\
\downarrow \text { edema }\end{array}$ & $\begin{array}{l}\text { Mukherjee } \\
\text { et al., 2011 } \\
{[58]}\end{array}$ \\
\hline In vivo/mice & $\begin{array}{c}\text { Cumulative dose of } 24 \\
\mathrm{mg} / \mathrm{kg} \& \text { a single dose of } \\
8 \mathrm{mg} / \mathrm{kg} \text { at } 3 \text {-week } \\
\text { intervals; i.p. }\end{array}$ & $\begin{array}{l}\downarrow \text { Body weight, heart } \\
\text { weight, and ratio of } \\
\text { heart weight to body } \\
\text { weight, } \uparrow \mathrm{LDH} \text {, protein } \\
\text { carbonyl content, and } \\
\text { MDA levels, } \uparrow \text { apoptosis, } \\
\uparrow \text { SIRT1 expression, } \\
\uparrow \text { acetylation of p53, } \\
\uparrow \text { binding activity of p53 } \\
\text { to BAX promoter } \\
\text { sequence, } \uparrow \text { BAX } \\
\text { expression, } \uparrow \text { cytosolic }\end{array}$ & $\begin{array}{c}15 \mathrm{mg} / \mathrm{kg} / \mathrm{day} \& \text { for } 7 \\
\text { weeks; diet }\end{array}$ & $\begin{array}{l}\uparrow \text { Body weight, heart } \\
\text { weight, and ratio of } \\
\text { heart weight to body } \\
\text { weight, } \downarrow \text { LDH, protein } \\
\text { carbonyl content, and } \\
\text { MDA levels, } \downarrow \text { apoptosis, } \\
\uparrow \uparrow S \text { SIRT1 expression, } \\
\downarrow \text { acetylation of p53, } \\
\downarrow \text { binding activity of p53 } \\
\text { to BAX promoter } \\
\text { sequence, } \downarrow \text { BAX } \\
\text { expression, } \downarrow \text { cytosolic }\end{array}$ & $\begin{array}{c}\text { Zhang et al., } \\
2011 \text { [47] }\end{array}$ \\
\hline
\end{tabular}


TABle 2: Continued.

\begin{tabular}{|c|c|c|c|c|c|}
\hline Model & $\begin{array}{l}\text { DOX dosage \& protocol } \\
\text { of usage; administration } \\
\text { route }\end{array}$ & $\begin{array}{l}\text { Outcomes of DOX on } \\
\text { cardiac cells/tissue }\end{array}$ & $\begin{array}{c}\text { Resveratrol dosage \& } \\
\text { protocol of usage; } \\
\text { administration route }\end{array}$ & $\begin{array}{c}\text { Resveratrol } \\
\text { coadministration } \\
\text { outcomes }\end{array}$ & $\begin{array}{l}\text { Author \& } \\
\text { year }\end{array}$ \\
\hline In vivo/rats & $\begin{array}{c}1 \text { and } 2 \mathrm{mg} / \mathrm{kg} \& \text { once a } \\
\text { week for seven weeks; } \\
\text { i.p. }\end{array}$ & $\begin{array}{c}\text { concentration of } \\
\text { cytochrome c, } \downarrow \text { release } \\
\text { of cytochrome c from } \\
\text { mitochondria } \\
\uparrow \mathrm{FABP} \text { and BNP levels } \\
\text { (for } 2 \mathrm{mg} / \mathrm{kg} \text { ), } \downarrow \text { creatine } \\
\text { kinase, } \mathrm{LDH} \text {, and ALP } \\
\text { levels (for } 2 \mathrm{mg} / \mathrm{kg} \text { ), } \\
\uparrow \mathrm{MDA}+4 \mathrm{HAE}, \downarrow \mathrm{GSH} / \\
\mathrm{GSSG} \text { ratio (for } 2 \mathrm{mg} / \\
\mathrm{kg} \text { ), } \downarrow \mathrm{SOD} \text { (for } 2 \mathrm{mg} / \mathrm{kg} \text { ), } \\
\text { induction of histological } \\
\text { changes ( } \uparrow \text { interstitial } \\
\text { edema, necrosis, and } \\
\text { inflammatory } \\
\text { infiltration) }\end{array}$ & $\begin{array}{c}20 \mathrm{mg} / \mathrm{kg} \text { (of feed) \& one } \\
\text { week prior to DOX } \\
\text { treatment }+ \\
\text { concomitantly with } \\
\text { DOX until end of } \\
\text { treatment; diet }\end{array}$ & $\begin{array}{l}\downarrow \text { FABP and BNP levels } \\
\text { (for } 2 \mathrm{mg} / \mathrm{kg} \text { ), } \downarrow \mathrm{MDA} \\
+4 \mathrm{HAE} \text { (for } 1 \mathrm{mg} / \mathrm{kg} \text { ), } \\
\downarrow \text { SOD (for } 1 \mathrm{mg} / \mathrm{kg} \text { ), } \\
\text { alleviation of DOX- } \\
\text { induced histological } \\
\text { changes }\end{array}$ & $\begin{array}{l}\text { Dudka } \\
\text { et al., } 2012 \\
{[55]}\end{array}$ \\
\hline In vivo/mice & $\begin{array}{l}\text { Cumulative dose of } 12 \\
\mathrm{mg} / \mathrm{kg} \text { \& six times over } 2 \\
\text { weeks; i.p. }\end{array}$ & $\begin{array}{l}\downarrow \text { Body weight, heart } \\
\text { weight, and ratio of } \\
\text { heart weight to body } \\
\text { weight, } \uparrow \text { serum creatine } \\
\text { kinase and LDH levels, } \\
\uparrow \text { apoptosis, } \uparrow \text { p53 } \\
\text { expression, } \uparrow \text { BAX } \\
\text { protein, } \downarrow \text { Bcl-2 protein, } \\
\uparrow \text { caspase- } 3 \text { activity, } \\
\downarrow \text { HO- } 1 \text { expression and } \\
\text { enzymatic activity }\end{array}$ & $\begin{array}{l}10 \mathrm{mg} / \mathrm{kg} / \text { day \& } 1 \text { week } \\
\text { prior to DOX injection } \\
\text { until two weeks after the } \\
\text { last DOX injection (end } \\
\text { of treatment); gavage }\end{array}$ & $\begin{array}{c}\uparrow \text { Body weight, heart } \\
\text { weight, and ratio of } \\
\text { heart weight to body } \\
\text { weight, } \downarrow \text { serum creatine } \\
\text { kinase and LDH levels, } \\
\downarrow \text { apoptosis, } \downarrow \text { p53 } \\
\text { expression, } \downarrow \text { BAX } \\
\text { protein, } \uparrow \text { Bcl- } 2 \text { protein, } \\
\downarrow \text { caspase- } 3 \text { activity, } \\
\uparrow \text { HO- } 1 \text { expression and } \\
\text { enzymatic activity }\end{array}$ & $\begin{array}{l}\text { Gu et al., } \\
2012[48]\end{array}$ \\
\hline $\begin{array}{l}\text { In vitro/neonatal } \\
\text { rat ventricular } \\
\text { cardiomyocytes }\end{array}$ & $1 \mu \mathrm{M} \& 18 \mathrm{~h}$ & $\begin{array}{c}\uparrow \text { Cell death ( } \uparrow \text { PI-positive } \\
\text { cells, cleaved caspase- } 3 \text {, } \\
\text { and PARP), } \text { autophagy } \\
\text { ( } \uparrow \text { AV-positive cells, } \\
\text { LC3-II, Atg5, and Atg5* } \\
\text { 12, } \downarrow \text { p62, } \uparrow \text { phospho- } \\
\text { S6K1, phospho-S6, and } \\
\text { phospho-MBP) }\end{array}$ & $\begin{array}{c}10 \mu \mathrm{M} \& 12 \mathrm{~h} \text { prior to } \\
\text { treatment }\end{array}$ & $\begin{array}{l}\downarrow \text { Cell death ( } \downarrow \text { PI-positive } \\
\text { cells, cleaved caspase-3, } \\
\text { and PARP), } \downarrow \text { autophagy } \\
\text { ( } \downarrow \text { AV-positive cells, } \\
\text { LC3-II, Atg5, and Atg5* } \\
\text { 12, } \uparrow \text { p62, } \downarrow \text { phospho- } \\
\text { S6K1, phospho-S6, and } \\
\text { phospho-MBP) }\end{array}$ & $\begin{array}{l}\text { Xu et al., } \\
2012[36]\end{array}$ \\
\hline In vivo/mice & $\begin{array}{l}8 \mathrm{mg} / \mathrm{kg} / \text { week } \& \text { for a } \\
\text { total of } 4 \text { weeks; i.p. }\end{array}$ & $\begin{array}{c}\downarrow \text { Body weight, heart } \\
\text { weight, and heart weight } \\
\text { to tibia length ratio, } \\
\uparrow \text { atrial natriuretic } \\
\text { peptide, } \downarrow \text { SERCA2a, } \\
\uparrow \text { ROS, } \downarrow \text { MnSOD, } \\
\downarrow \text { mitochondrial electron } \\
\text { transport chain } \\
\text { complexes I and II }\end{array}$ & $\begin{array}{c}320 \mathrm{mg} / \mathrm{kg} / \mathrm{day} \& \text { for } 8 \\
\text { weeks; diet }\end{array}$ & $\begin{array}{c}\downarrow \text { Atrial natriuretic } \\
\text { peptide, } \downarrow \text { ROS, } \\
\uparrow M n S O D, \\
\uparrow \text { mitochondrial electron } \\
\text { transport chain } \\
\text { complexes I, II, and IV, } \\
\uparrow \text { mitofusin-1 and } \\
\text { mitofusin-2 levels }\end{array}$ & $\begin{array}{c}\text { Dolinsky } \\
\text { et al., } 2013 \\
{[50]}\end{array}$ \\
\hline In vivo/mice & $\begin{array}{c}20 \mathrm{mg} / \mathrm{kg} \& \text { single dose; } \\
\text { i.p. }\end{array}$ & $\begin{array}{l}\text { Areas of myocytolysis } \\
\text { with congestion of blood } \\
\text { vessels, cytoplasmic } \\
\text { vacuolization and } \\
\text { fragmentation, } \\
\text { hyalinization of muscle } \\
\text { fiber, and chromatin } \\
\text { margination of some } \\
\text { nuclei, some pyknotic } \\
\text { nuclei }\end{array}$ & $\begin{array}{l}\text { Single dose of } 15 \mathrm{mg} / \mathrm{kg} \\
\quad \& \text { cotreatment; i.p. }\end{array}$ & $\begin{array}{l}\text { Normal muscle fibers } \\
\text { with central oval nuclei } \\
\text { and some pyknotic } \\
\text { nuclei, fragmentation of } \\
\text { the muscle fiber }\end{array}$ & $\begin{array}{c}\text { Osman } \\
\text { et al., 2013 } \\
{[62]}\end{array}$ \\
\hline In vivo/rats & $\begin{array}{c}12 \mathrm{mg} / \mathrm{kg} \text { \& single dose; } \\
\text { i.p. }\end{array}$ & & $\begin{array}{l}100 \mathrm{mg} / \mathrm{kg} \& \text { for } 3 \text { times } \\
\text { (first one week before }\end{array}$ & $\begin{array}{c}\downarrow \text { Necrosis and } \uparrow \text { normal } \\
\text { myocardium }\end{array}$ & \\
\hline
\end{tabular}


TABle 2: Continued.

\begin{tabular}{|c|c|c|c|c|c|}
\hline Model & $\begin{array}{l}\text { DOX dosage \& protocol } \\
\text { of usage; administration } \\
\text { route }\end{array}$ & $\begin{array}{l}\text { Outcomes of DOX on } \\
\text { cardiac cells/tissue }\end{array}$ & $\begin{array}{c}\text { Resveratrol dosage } \& \\
\text { protocol of usage; } \\
\text { administration route }\end{array}$ & $\begin{array}{c}\text { Resveratrol } \\
\text { coadministration } \\
\text { outcomes }\end{array}$ & $\begin{array}{l}\text { Author \& } \\
\text { year }\end{array}$ \\
\hline & & $\begin{array}{c}\uparrow E \text { Edema and necrosis } \\
\text { without normal } \\
\text { myocardium }\end{array}$ & $\begin{array}{l}\text { and the others with } \\
\text { weekly intervals after } \\
\text { DOX treatment); i.p. }\end{array}$ & & $\begin{array}{l}\text { Pinarlı } \\
\text { et al., } 2013 \\
{[63]}\end{array}$ \\
\hline In vivo/rats & $\begin{array}{c}20 \mathrm{mg} / \mathrm{kg} \text { \& single dose; } \\
\text { i.p. }\end{array}$ & $\begin{array}{c}\uparrow \text { Serum CPK and LDH } \\
\text { enzymes, } \uparrow \mathrm{MDA}, \downarrow \mathrm{GSH} \text {, } \\
\downarrow \text { TAC, massive } \\
\text { fragmentation and lysis } \\
\text { of myofibrils, } \\
\text { vacuolization or } \\
\text { complete loss of cristae, } \\
\text { interruption of } \mathrm{Z} \text { lines }\end{array}$ & $\begin{array}{c}10 \mathrm{mg} / \mathrm{kg} \& \text { cotreatment; } \\
\text { i.p. }\end{array}$ & $\begin{array}{c}\downarrow \text { Serum CPK and LDH } \\
\text { enzymes, } \downarrow \text { MDA, } \uparrow \text { GSH, } \\
\uparrow T A C \text {, organized } \\
\text { myofibrils with } \\
\text { mitochondria in } \\
\text { between, preservation of } \\
\text { mitochondria structure } \\
\text { similar to those of } \\
\text { control group, } \\
\text { observation of focal } \\
\text { areas of myofibrillar loss } \\
\text { and dilated sarcoplasmic } \\
\text { reticulum }\end{array}$ & $\begin{array}{l}\text { Al-Harthi } \\
\text { et al., } 2014 \\
{[54]}\end{array}$ \\
\hline In vivo/rats & $\begin{array}{c}\text { Accumulative dose of } 15 \\
\mathrm{mg} / \mathrm{kg} \& 2.5 \mathrm{mg} / \mathrm{kg} \text { in } \\
\text { six injections for } 2 \\
\text { weeks; i.p. }\end{array}$ & $\begin{array}{c}\downarrow \text { Body weight, absolute } \\
\text { and relative heart } \\
\text { weights, } \uparrow \mathrm{CK}-\mathrm{MB} \text {, } \\
\uparrow \mathrm{MDA}, \downarrow \mathrm{GSH}, \downarrow \text { SOD, } \\
\uparrow \text { hydroxyproline, } \uparrow \mathrm{TNF}- \\
\alpha \text {, myocardial cell injury } \\
\text { (necrosis, rupture of } \\
\text { cardiac muscle fibers, } \\
\text { myocyte wavy } \\
\text { degeneration, massive } \\
\text { interstitial hemorrhage, } \\
\text { and interfibrillar } \\
\text { congestion), } \uparrow \text { caspase-3 } \\
\text { and TGF- } \beta 1 \text { gene } \\
\text { expression, } \uparrow \text { interstitial } \\
\text { fibrosis, massive } \\
\text { deposition of collagen }\end{array}$ & $\begin{array}{c}20 \mathrm{mg} / \mathrm{kg} / \mathrm{day} \& \text { for } 4 \\
\text { weeks (starting } 2 \text { weeks } \\
\text { prior to DOX } \\
\text { administration); gavage }\end{array}$ & $\begin{array}{c}\uparrow \text { Body weight, absolute } \\
\text { and relative heart } \\
\text { weights, } \downarrow \mathrm{CK}-\mathrm{MB} \text {, } \\
\downarrow \mathrm{MDA}, \uparrow \mathrm{GSH}, \uparrow \mathrm{SOD}, \\
\downarrow \text { hydroxyproline, } \downarrow \mathrm{TNF}- \\
\alpha \text {, moderate interstitial } \\
\text { hemorrhage, necrosis, } \\
\text { and fibrosis, } \downarrow \text { caspase-3 } \\
\text { and TGF- } \beta 1 \text { gene } \\
\text { expression, } \downarrow \text { interstitial } \\
\text { fibrosis }\end{array}$ & $\begin{array}{l}\text { Arafa et al., } \\
2014 \text { [49] }\end{array}$ \\
\hline $\begin{array}{l}\text { In vitro/H9c2 } \\
\text { cells }\end{array}$ & $2 \mu \mathrm{M} \& 12 \mathrm{~h}$ & $\begin{array}{c}\downarrow \text { Cell viability, } \\
\uparrow \mathrm{AMPK} \alpha 2 \text { and E2F1 } \\
\text { expression, } \uparrow \text { cleaved } \\
\text { PARP and caspase-3 } \\
\text { levels }\end{array}$ & $250 \mu \mathrm{M} \&$ cotreatment & $\begin{array}{c}\uparrow \text { Cell viability, } \\
\downarrow \text { AMPK } \alpha 2 \text { and E2F1 } \\
\text { expression, } \downarrow \text { cleaved } \\
\text { PARP and caspase-3 } \\
\text { levels }\end{array}$ & $\begin{array}{l}\text { Yang et al., } \\
2014 \text { [37] }\end{array}$ \\
\hline $\begin{array}{l}\text { In vitro/human } \\
\text { cardiac } \\
\text { progenitor cells } \\
\text { and in vivo/rats }\end{array}$ & $\begin{array}{l} \\
0.5 \mu \mathrm{M} \& 24 \mathrm{~h} \text { (for } \\
\text { in vitro) and cumulative } \\
\text { dose of } 15 \mathrm{mg} / \mathrm{kg} \& \text { for } 6 \\
\text { times with dose of } 2.5 \\
\mathrm{mg} / \mathrm{kg} \text { over a period of } 2 \\
\text { weeks; i.p. (for in vivo) }\end{array}$ & $\begin{array}{c}\downarrow \text { Body weight and } \\
\text { ascites, } \downarrow \text { survival, } \\
\downarrow \text { phospho-SIRT1 }{ }^{\text {Ser27 }} \text {, } \\
\uparrow \text { ROS, } \uparrow \text { expression levels } \\
\text { of acetyl-p53 }{ }^{\text {Lyss373 }} \text { and } \\
\text { acetyl-p53 } 3^{\text {Lys } 382}, \\
\uparrow \text { apoptosis, } \downarrow \text { expression } \\
\text { levels of IGF-1R and } \\
\text { phospho-Akt } \\
\text { ver473 }, \downarrow \text { cell } \\
\text { viability, } \uparrow \text { senescence } \\
\left(\uparrow \text { p16 } 6^{\text {INK4a }} \text { and } \beta \text { - }\right. \\
\text { galactosidase levels), } \\
\uparrow \text { DNA damage, } \\
\downarrow \text { migration ability }\end{array}$ & $\begin{array}{l}0.5 \mu \mathrm{M} \& \text { cotreatment } \\
\text { (for in vitro) and } 2.5 \mathrm{mg} / \\
\mathrm{kg} / \text { day \& for } 6 \text { weeks } \\
\text { (concomitantly with } \\
\text { DOX administration } \\
\text { and then were } \\
\text { maintained for four } \\
\text { more weeks); gavage (for } \\
\text { in vivo) }\end{array}$ & $\begin{array}{c}\uparrow \text { Body weight and } \\
\text { ascites, } \uparrow \text { survival, } \\
\uparrow \text { SIRT1 expression, } \\
\uparrow \text { phospho-SIRT1 }{ }^{\text {Ser }} \\
27, \uparrow \text { catalase and } \\
\text { MnSOD, } \downarrow \text { ROS, } \\
\downarrow \text { expression levels of } \\
\text { acetyl-p53 }{ }^{\text {Lys3373 }} \text { and } \\
\text { acetyl-p53 }{ }^{\text {Lys } 382}, \\
\downarrow \text { apoptosis, } \uparrow \text { expression } \\
\text { levels of IGF-1R and } \\
\text { phospho-Akt } \\
\text { viability, } \uparrow \text { cell } \\
\downarrow \text { senescence } \\
\text { ( } \downarrow \text { p16 } 6^{\text {INK4a and } \beta-} \\
\text { galactosidase levels), }\end{array}$ & $\begin{array}{c}\text { De Angelis } \\
\text { et al., } 2015 \\
{[38]}\end{array}$ \\
\hline
\end{tabular}


TABLE 2: Continued.

\begin{tabular}{|c|c|c|c|c|c|}
\hline Model & $\begin{array}{l}\text { DOX dosage \& protocol } \\
\text { of usage; administration } \\
\text { route }\end{array}$ & $\begin{array}{l}\text { Outcomes of DOX on } \\
\text { cardiac cells/tissue }\end{array}$ & $\begin{array}{l}\text { Resveratrol dosage \& } \\
\text { protocol of usage; } \\
\text { administration route }\end{array}$ & $\begin{array}{c}\text { Resveratrol } \\
\text { coadministration } \\
\text { outcomes }\end{array}$ & $\begin{array}{l}\text { Author \& } \\
\text { year }\end{array}$ \\
\hline $\begin{array}{l}\text { In vitro/H9c2 } \\
\text { cells }\end{array}$ & $5 \mu \mathrm{M} \& 24 \mathrm{~h}$ & $\begin{array}{c}\downarrow \text { Cell viability, } \\
\uparrow \text { apoptosis ( } \uparrow \text { GRP78 and } \\
\text { CHOP expression), } \\
\uparrow \text { SIRT1 level }\end{array}$ & $\begin{array}{l}25 \mu \mathrm{M} \& \text { for } 24 \mathrm{~h} \text { prior } \\
\text { to DOX treatment }\end{array}$ & $\begin{array}{c}\downarrow \text { DNA damage, } \\
\uparrow \text { migration ability } \\
\uparrow \text { Cell viability, } \\
\downarrow \text { apoptosis ( } \downarrow \text { GRP78 and } \\
\text { CHOP expression), } \\
\uparrow \uparrow S I R T 1 \text { level }\end{array}$ & $\begin{array}{l}\text { Lou et al., } \\
2015 \text { [39] }\end{array}$ \\
\hline In vivo/mice & $\begin{array}{c}20 \mathrm{mg} / \mathrm{kg} \& \text { single dose; } \\
\text { i.p. }\end{array}$ & $\begin{array}{c}\uparrow R O S, \uparrow \text { apoptosis, } \\
\downarrow \text { SIRT1, } \uparrow \text { cleaved } \\
\text { caspase- } 3, \uparrow \text { BAX, } \downarrow \text { Bcl-2, } \\
\uparrow \text { phosphorylation- } \\
\text { p38MAPK }\end{array}$ & $\begin{array}{c}10 \mathrm{mg} / \mathrm{kg} / \mathrm{day} \& \text { for } 8 \\
\text { days ( } 3 \text { days prior to } \\
\text { DOX injection \& } 5 \text { days } \\
\text { after the injection); } \\
\text { gavage }\end{array}$ & $\begin{array}{c}\downarrow R O S, \downarrow \text { apoptosis, } \\
\uparrow \text { SIRT1, } \downarrow \text { cleaved } \\
\text { caspase-3, } \downarrow \text { BAX, } \uparrow \text { Bcl-2, } \\
\downarrow \text { phosphorylation- } \\
\text { p38MAPK }\end{array}$ & $\begin{array}{l}\text { Ruan et al., } \\
2015 \text { [59] }\end{array}$ \\
\hline In vivo/mice & $\begin{array}{l}18 \mathrm{mg} / \mathrm{kg} \& \text { single dose } \\
\text { on day } 1 ; \text { i.p. }\end{array}$ & $\begin{array}{c}\downarrow \text { Deacetylase activity of } \\
\text { SIRT1, } \uparrow \text { protein content } \\
\text { of p300, } \uparrow \text { acetylated } \\
\text { Foxo1, } \uparrow \text { protein level of } \\
\text { MuRF-1, } \uparrow \text { ubiquitinated } \\
\text { proteins, } \uparrow \text { basal } \\
\text { proteasomal activity and } \\
\text { protein level of USP7, } \\
\uparrow \text { p53, } \uparrow \text { BAX, } \uparrow \text { caspase-3 } \\
\text { activity, } \uparrow \text { apoptotic } \\
\text { DNA fragmentation }\end{array}$ & $\begin{array}{l}20 \mathrm{mg} / \mathrm{kg} / \text { day } \& \text { from } \\
\text { day } 2 \text { to day } 4 \text {; i.p. }\end{array}$ & $\begin{array}{c}\uparrow \text { Deacetylase activity of } \\
\text { SIRT1, } \downarrow \text { protein content } \\
\text { of p300, } \downarrow \text { acetylated } \\
\text { Foxo } 1, \downarrow \text { protein level of } \\
\text { MuRF- } 1, \downarrow \text { ubiquitinated } \\
\text { proteins, } \downarrow \text { basal } \\
\text { proteasomal activity and } \\
\text { protein level of USP7, } \\
\downarrow \text { p53, } \downarrow \text { BAX, } \downarrow \text { caspase-3 } \\
\text { activity, } \downarrow \text { apoptotic } \\
\text { DNA fragmentation }\end{array}$ & $\begin{array}{l}\text { Sin et al., } \\
2015[60]\end{array}$ \\
\hline In vivo/mice & $\begin{array}{l}5,5 \text {, and } 15 \mathrm{mg} / \mathrm{kg} \text { in } \\
\text { days } 2,8 \text {, and } 14 ; \text { i.p. }\end{array}$ & $\begin{array}{c}\uparrow \text { Plasma LDH, } \downarrow \text { plasma } \\
\text { catalase, GPx, GSH, and } \\
\text { T-SOD, } \uparrow \text { plasma MDA, } \\
\downarrow \text { activity of } \mathrm{Ca}^{+}{ }^{-} \\
\text {ATPase }\end{array}$ & $\begin{array}{c}200 \mu \mathrm{mol} / \mathrm{kg} / \text { day \& for } \\
15 \text { days; intragastric }\end{array}$ & $\begin{array}{c}\uparrow \text { Plasma catalase and } \mathrm{T}- \\
\text { SOD }\end{array}$ & $\begin{array}{l}\text { Wang et al., } \\
2015[61]\end{array}$ \\
\hline In vivo/rats & $\begin{array}{l}\text { Cumulative dose of } 15 \\
\mathrm{mg} / \mathrm{kg} \& 6 \text { injections of } \\
2.5 \mathrm{mg} / \mathrm{kg} \text { over a period } \\
\text { of } 2 \text { weeks; i.p. }\end{array}$ & $\begin{array}{c}\downarrow \text { Survival, } \uparrow \text { apoptotic } \\
\text { myocytes and 8-OH-dG, } \\
\uparrow \text { acetyl-p53 } 3^{\text {Lys381 }} \text { level, } \\
\uparrow \text { myocardial collagen I } \\
\text { mRNA expression and } \\
\text { collagen I/III, } \downarrow \text { SIRT1 } \\
\text { mRNA expression, } \\
\uparrow \text { deacetylase activity of } \\
\text { SIRT1, } \uparrow \text { mRNA level } \\
\text { and protein expression } \\
\text { of TGF- } \beta \text { and phospho- } \\
\text { SMAD3 } 3^{\text {Ser423/425/ }} \\
\text { SMAD3 ratio, } \uparrow \alpha \text {-SMA, } \\
\text { FAP1 } \alpha \text {, CTGF, and } \\
\text { MMP-2 levels, } \\
\uparrow \text { gelatinolytic activity of } \\
\text { MMP-2 in myocardium, } \\
\uparrow \text { fibronectin }\end{array}$ & $\begin{array}{l}2.5 \mathrm{mg} / \mathrm{kg} / \text { day \& } \\
\text { concomitantly with } \\
\text { DOX administration } \\
\text { and then were } \\
\text { maintained for one more } \\
\text { week; gavage }\end{array}$ & 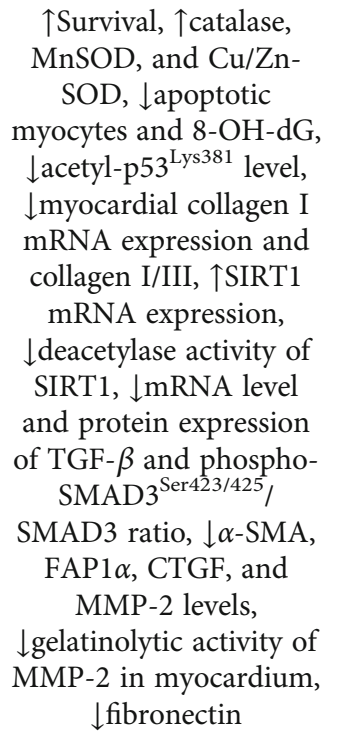 & $\begin{array}{c}\text { Cappetta } \\
\text { et al., } 2016 \\
{[44]}\end{array}$ \\
\hline $\begin{array}{l}\text { In vitro/H9c2 } \\
\text { cells and in vivo/ } \\
\text { rats }\end{array}$ & $\begin{array}{c}2 \mu M \& 24 \mathrm{~h} \text { (for } \\
\text { in vitro) and } 15 \mathrm{mg} / \mathrm{kg} / \\
\text { day \& for } 1 \text { week; i.p. } \\
\text { (for in vivo) }\end{array}$ & $\begin{array}{c}\uparrow \text { Apoptosis, } \downarrow \text { phospho- } \\
\text { AMPK, } \uparrow \text { Beclin-1, } \\
\uparrow \text { cleaved caspase- } 3, \\
\downarrow \text { Bcl- } 2, \uparrow \text { BAX, } \\
\uparrow \text { phospho-p53, } \\
\uparrow \text { phospho-p38MAPK }\end{array}$ & $\begin{array}{c}20 \mu M \text { \& cotreatment } \\
\text { (for in vitro) } / 10 \mathrm{mg} / \mathrm{kg} / \\
\text { day \& cotreatment; i.p. } \\
\text { (for in vivo) }\end{array}$ & $\begin{array}{c}\downarrow \text { Apoptosis, } \uparrow \text { phospho- } \\
\text { AMPK, } \uparrow \text { LC3-II/LC3-I, } \\
\uparrow \uparrow \text { Beclin-1, } \downarrow \text { cleaved } \\
\text { caspase- } 3, \uparrow \text { Bcl-2, } \downarrow \text { BAX, } \\
\downarrow \text { phospho-p53, } \\
\downarrow \text { phospho-p38MAPK }\end{array}$ & $\begin{array}{l}\text { Gu et al., } \\
2016[57]\end{array}$ \\
\hline $\begin{array}{l}\text { In vitro/H9c2 } \\
\text { cells }\end{array}$ & $5 \mu \mathrm{M} \& 24 \mathrm{~h}$ & $\begin{array}{c}\downarrow \text { Cell viability, } \\
\downarrow \text { phospho-AMPK, } \uparrow \mathrm{p} 53,\end{array}$ & $\begin{array}{c}25 \mu \mathrm{M} \& 30 \text { min prior to } \\
\text { DOX treatment }\end{array}$ & $\begin{array}{c}\uparrow \text { Cell viability, } \\
\uparrow \text { phospho-AMPK, } \downarrow \text { p53, }\end{array}$ & $\begin{array}{l}\text { Liu et al., } \\
2016[40]\end{array}$ \\
\hline
\end{tabular}


TABle 2: Continued.

\begin{tabular}{|c|c|c|c|c|c|}
\hline Model & $\begin{array}{l}\text { DOX dosage \& protocol } \\
\text { of usage; administration } \\
\text { route }\end{array}$ & $\begin{array}{l}\text { Outcomes of DOX on } \\
\text { cardiac cells/tissue }\end{array}$ & $\begin{array}{c}\text { Resveratrol dosage \& } \\
\text { protocol of usage; } \\
\text { administration route }\end{array}$ & $\begin{array}{c}\text { Resveratrol } \\
\text { coadministration } \\
\text { outcomes }\end{array}$ & $\begin{array}{l}\text { Author \& } \\
\text { year }\end{array}$ \\
\hline $\begin{array}{l}\text { In vitro/H9c2 } \\
\text { cells }\end{array}$ & $5 \mu \mathrm{M} \& 24 \mathrm{~h}$ & $\begin{array}{c}\uparrow \text { BAX, } \downarrow \text { Bcl-2, } \\
\uparrow \text { apoptosis } \\
\downarrow \text { Cell viability, } \\
\uparrow \text { apoptosis, } \downarrow \text { SIRT1 } \\
\text { level, } \uparrow \text { FoxO1, p53, and } \\
\text { Bim levels, } \downarrow \text { SOD, } \\
\uparrow \text { MDA, } \uparrow \text { LDH }\end{array}$ & $\begin{array}{c}25 \mu \mathrm{M} \& 24 \mathrm{~h} \text { prior to } \\
\text { DOX treatment }\end{array}$ & $\begin{array}{c}\downarrow \text { BAX, } \uparrow \text { Bcl-2, } \\
\downarrow \text { apoptosis } \\
\uparrow \text { Cell viability, } \\
\downarrow \text { apoptosis, } \uparrow \text { SIRT1 } \\
\text { level, } \downarrow \text { FoxO1, p53, and } \\
\text { Bim levels, } \uparrow \text { SOD, } \\
\downarrow \text { MDA, } \downarrow \text { LDH }\end{array}$ & $\begin{array}{l}\text { Liu et al., } \\
2016[41]\end{array}$ \\
\hline $\begin{array}{l}\text { In vitro/H9c2 } \\
\text { cells }\end{array}$ & $3 \mu \mathrm{mol} / \mathrm{L} \&$ for $24 \mathrm{~h}$ & $\begin{array}{c}\downarrow \text { Cell viability, } \uparrow \text { cleaved } \\
\text { PARP and cleaved } \\
\text { caspase-3 }\end{array}$ & 2 and $100 \mu \mathrm{mol} / \mathrm{L} \& \mathrm{NI}$ & $\begin{array}{c}\uparrow \text { Cell viability, } \downarrow \text { cleaved } \\
\text { PARP and cleaved } \\
\text { caspase-3 (for } 100 \mu \mathrm{mol} / \\
\text { L) }\end{array}$ & $\begin{array}{l}\text { Yang et al., } \\
2016[42]\end{array}$ \\
\hline $\begin{array}{l}\text { In vitro/neonatal } \\
\text { rat } \\
\text { cardiomyocytes }\end{array}$ & $10 \mu \mathrm{M} \& 6 \mathrm{~h}$ & $\uparrow$ Apoptosis & $\begin{array}{c}2.5 \mu \mathrm{M} \text { or } 250 \mathrm{nM}(\mathrm{NI}) \\
\& 48 \mathrm{~h}\end{array}$ & $\begin{array}{l}\text { No change on DOX- } \\
\text { induced apoptosis }\end{array}$ & $\begin{array}{l}\text { du Pré et al., } \\
2017 \text { [101] }\end{array}$ \\
\hline In vivo/rats & $\begin{array}{l}\text { Cumulative dose } 2.5 \mathrm{mg} / \\
\text { kg \& six equal doses } \\
\text { during } 2 \text { weeks; i.p. }\end{array}$ & $\begin{array}{c}\downarrow \text { Body weight, } \uparrow \text { NFAT3 } \\
\text { level, } \downarrow \text { NFAT5 level, } \\
\text { induction of histological } \\
\text { changes (widely spaced } \\
\text { deep acidophilic fibers, } \\
\text { dense collagen fibers } \\
\text { among thin fibers), } \\
\uparrow \text { CK-MB and LDH, } \\
\uparrow B A X, \downarrow \text { Bcl-xL, } \\
\uparrow \text { caspase-3 expression }\end{array}$ & $\begin{array}{l}20 \mathrm{mg} / \mathrm{kg} / \text { day \& for } 6 \\
\text { weeks (concomitantly } \\
\text { with DOX } \\
\text { administration for } 2 \\
\text { weeks and then was } \\
\text { continued for next } 4 \\
\text { weeks); oral }\end{array}$ & $\begin{array}{c}\uparrow \text { Body weight, } \downarrow \text { NFAT3 } \\
\text { level, } \uparrow \text { NFAT5 level, } \\
\text { alleviation of DOX- } \\
\text { induced histological } \\
\text { changes (few congested } \\
\text { blood vessels among } \\
\text { muscle fibers, few deeply } \\
\text { acidophilic, and few thin } \\
\text { attenuated fibers, } \\
\downarrow \text { fibrosis), } \downarrow \text { CK-MB and } \\
\text { LDH, } \downarrow \text { BAX, } \uparrow \text { Bcl-xL, } \\
\downarrow \text { caspase-3 expression }\end{array}$ & $\begin{array}{l}\text { Shoukry } \\
\text { et al., } 2017 \\
{[51]}\end{array}$ \\
\hline $\begin{array}{l}\text { In vitro/H9c2 } \\
\text { cells and in vivo/ } \\
\text { mice (normal and } \\
\text { AMI mice) }\end{array}$ & $\begin{array}{c}1 \mu \mathrm{M} \& 24 \mathrm{~h} \text { (for } \\
\text { in vitro) and cumulative } \\
\text { dose of } 20 \mathrm{mg} / \mathrm{kg} \& 4 \\
\text { times over } 4 \text { weeks; i.p. } \\
\text { (for in vitro \& normal } \\
\text { mice) and } 5 \mathrm{mg} / \mathrm{kg} / \text { day } \\
\text { \& for } 7 \text { days; i.p. (for } \\
\text { in vitro \& AMI mice) }\end{array}$ & $\begin{array}{c}\uparrow \text { Apoptosis, } \uparrow \text { E2F1, } \\
\uparrow \mathrm{mTORC} 1, \downarrow \text { LC3-II/ } \\
\text { LC3-I, } \uparrow \text { AMPK } \alpha 2, \\
\uparrow \text { cleaved caspase-3 }\end{array}$ & $\begin{array}{l}20 \mu \mathrm{M} \& \text { cotreatment } \\
\text { (for in vitro) and } \\
\text { cumulative dose of } 10 \\
\mathrm{mg} / \mathrm{kg} / \text { injection \& prior } \\
\text { to each DOX injection; } \\
\text { i.p. (for in vitro \& } \\
\text { normal mice) and } 10 \\
\mathrm{mg} / \mathrm{kg} / \text { day \& for } 7 \text { days; } \\
\text { i.p. (for in vitro \& AMI } \\
\text { mice) }\end{array}$ & $\begin{array}{c}\downarrow \text { Apoptosis, } \downarrow \text { E2F1, } \\
\downarrow \text { mTORC1, } \uparrow \text { LC3-II/ } \\
\text { LC3-I, } \downarrow \text { AMPK } \alpha 2, \\
\downarrow \text { cleaved caspase-3 }\end{array}$ & $\begin{array}{l}\text { Gu et al., } \\
2018[56]\end{array}$ \\
\hline In vivo/mice & $\begin{array}{l}4 \mathrm{mg} / \mathrm{kg} \& \text { once per } \\
\text { week for } 3 \text { weeks; i.p. }\end{array}$ & $\begin{array}{l}\downarrow \text { Heart weight, } \\
\uparrow \text { phospho-p38 }\end{array}$ & $\begin{array}{c}0.4 \% \text { of diet \& for } 4 \\
\text { weeks (starting one week } \\
\text { prior to DOX injections } \\
\text { and then was } \\
\text { discontinued at one } \\
\text { week after the last DOX } \\
\text { injection); diet }\end{array}$ & $\begin{array}{l}\uparrow \text { Heart weight, } \\
\downarrow \text { phospho-p38 }\end{array}$ & $\begin{array}{l}\text { Matsumura } \\
\text { et al., } 2018 \\
{[52]}\end{array}$ \\
\hline In vivo/mice & $\begin{array}{l}20 \mathrm{mg} / \mathrm{kg} \& \text { single dose } \\
\text { on day } 4 ; \text { i.p. }\end{array}$ & $\begin{array}{l}\downarrow \text { Body weight, } \downarrow \text { survival } \\
\text { rate, induction of } \\
\text { histological changes } \\
\text { (distortion of the } \\
\text { myocardial fibers and } \\
\text { the cells with vacuole } \\
\text { degeneration of various } \\
\text { sizes) }\end{array}$ & $\begin{array}{c}20 \mathrm{mg} / \mathrm{kg} / \text { day } \& \text { for } 9 \\
\text { days (4 days prior to } \\
\text { DOX injection and then } \\
\text { was continued for next } 5 \\
\text { days); i.g. }\end{array}$ & $\begin{array}{c}\uparrow \text { Body weight, } \uparrow \text { survival } \\
\text { rate, alleviation of DOX- } \\
\text { induced histological } \\
\text { changes }\end{array}$ & $\begin{array}{c}\text { Zhang et al., } \\
2019 \text { [45] }\end{array}$ \\
\hline In vivo/rats & $\begin{array}{l}\text { Cumulative dose of } 20 \\
\mathrm{mg} / \mathrm{kg} \& 2 \mathrm{mg} / \mathrm{kg} / \\
\text { injection and twice } / \text { week } \\
\text { for } 5 \text { weeks (from weeks } \\
22 \text { to 6); i.p. }\end{array}$ & $\begin{array}{c}\uparrow \text { Serum CK-MB, } \\
\text { troponin-I, and LDH } \\
\text { levels, foci of } \\
\text { degenerated } \\
\text { myocardium, infiltration }\end{array}$ & $\begin{array}{c}20 \mathrm{mg} / \mathrm{kg} / \text { day } \& \text { for } 6 \\
\text { weeks (starting one week } \\
\text { prior to DOX } \\
\text { administration); oral }\end{array}$ & $\begin{array}{c}\downarrow \text { Serum CK-MB, } \\
\text { troponin-I, and LDH } \\
\text { levels, foci of } \\
\text { degenerated } \\
\text { myocardium, } \downarrow \text { TLR-4, }\end{array}$ & $\begin{array}{l}\text { Alanazi } \\
\text { et al., 2020 } \\
\text { [53] }\end{array}$ \\
\hline
\end{tabular}


TABLE 2: Continued.

\begin{tabular}{|c|c|c|c|c|c|}
\hline Model & $\begin{array}{l}\text { DOX dosage \& protocol } \\
\text { of usage; administration } \\
\text { route }\end{array}$ & $\begin{array}{l}\text { Outcomes of DOX on } \\
\text { cardiac cells/tissue }\end{array}$ & $\begin{array}{l}\text { Resveratrol dosage } \& \\
\text { protocol of usage; } \\
\text { administration route }\end{array}$ & $\begin{array}{c}\text { Resveratrol } \\
\text { coadministration } \\
\text { outcomes }\end{array}$ & $\begin{array}{l}\text { Author \& } \\
\text { year }\end{array}$ \\
\hline $\begin{array}{l}\text { In vitro/H9c2 } \\
\text { cells and neonatal } \\
\text { rat } \\
\text { cardiomyocytes } \\
\text { and in vivo/rats }\end{array}$ & $\begin{array}{l}1 \mu \mathrm{mol} / \mathrm{L} \& 24 \mathrm{~h} \text { (for } \\
\text { in vitro) and } 10 \mathrm{mg} / \mathrm{kg} / \\
\text { injection \& twice/week } \\
\text { for } 2 \text { weeks (in the fifth } \\
\text { and sixth weeks); i.p. } \\
\text { (for in vivo) }\end{array}$ & $\begin{array}{c}\text { of inflammatory cells in } \\
\text { the endomysium, } \uparrow \text { TLR- } \\
4 \text {, TNF- } \alpha \text {, IL- } 6 \text {, and } \\
\text { iNOS expression levels, } \\
\uparrow \text { MDA, } \downarrow \text { GSH and SOD, } \\
\downarrow \text { S100A1 and SERCA2a } \\
\text { expression levels } \\
\downarrow \text { Cell viability, } \downarrow \text { heart } \\
\text { weight to body weight } \\
\text { ratio, } \uparrow \text { serum LDH and } \\
\text { CK-MB levels, } \\
\uparrow \text { apoptosis, } \uparrow B A X, \\
\downarrow \text { VEGF-B, phospho-Akt } \\
\text { and phospho-GSK-3 } \beta \\
\text { expressions }\end{array}$ & $\begin{array}{l}50 \mu \mathrm{mol} / \mathrm{L} \& 48 \mathrm{~h} \text { prior } \\
\text { to DOX treatment }+50 \\
\mu \mathrm{mol} / \mathrm{L} \& \text { cotreatment } \\
\text { (for in vitro) and } 50 \mathrm{mg} / \\
\mathrm{kg} / \text { day \& for } 6 \text { weeks; } \\
\text { gavage (for in vivo) }\end{array}$ & $\begin{array}{l}\uparrow \text { Cell viability, } \uparrow \text { heart } \\
\text { weight to body weight } \\
\text { ratio, } \downarrow \text { serum LDH and } \\
\text { CK-MB levels, } \\
\downarrow \text { apoptosis, } \downarrow \text { BAX, } \\
\uparrow \text { VEGF-B, phospho-Akt } \\
\text { and phospho-GSK-3 } \beta \\
\text { expressions }\end{array}$ & $\begin{array}{l}\text { Tian et al., } \\
2020[43]\end{array}$ \\
\hline
\end{tabular}

$\uparrow$ : increase; $\downarrow$ : decrease; NI: not informed; i.p.: intraperitoneal; i.g.: intragastrical; DOX: doxorubicin; MDA: malondialdehyde; ROS: reactive oxygen species; GPx: glutathione peroxidase; SOD: superoxide dismutase; MMP-2: matrix metalloproteinase-2; PARP: poly (ADP-ribose) polymerase; BAX: Bcl-2-associated X protein; Bcl-xL: B-cell lymphoma-extra large; IL-6: interleukin 6; TNF- $\alpha$ : tumor necrosis factor alpha; LDH: lactate dehydrogenase; FABP: fatty acid binding protein; BNP: brain natriuretic peptide; AST: aspartate aminotransferase; ALP: alkaline phosphatase; PI: propidium iodide; S6K1: p70 S6 kinase 1; SERCA2a: sarcoplasmic/endoplasmic reticulum calcium-ATPase 2a; MnSOD: manganese superoxide dismutase; CPK: creatine phosphokinase; GSH: glutathione; CKMB: creatine kinase-myocardial band; AMI: acute myocardial infarction; MPO: myeloperoxidase; T-SOD: total superoxide dismutase; SIRT1: sirtuin 1; TBARS: thiobarbituric acid reactive substances; HO-1: heme oxygenase-1; CPK: creatine phosphokinase; TGF- $\beta 1$ : transforming growth factor beta 1; TAC: total antioxidant capacity; IGF-1R: insulin-like growth factor 1 receptor; NFAT3: nuclear factor of activated T cells 3; mTORC1: mammalian target of rapamycin complex 1; AMPK: adenosine monophosphate- (AMP-) activated protein kinase; VEGF-B: vascular endothelial growth factor B; iNOS: inducible nitric oxide synthase; TLR-4: toll-like receptor-4.

Two hundred and eighteen articles were obtained by a systematic search on the above-mentioned electronic databases up to March 2021. After removing the duplicated articles $(n=95)$, the remaining ones $(n=123)$ were screened in their titles and abstracts, and 64 of them were excluded. Fifty-nine articles were qualified for evaluation of their full texts. Thirty-three articles were finally included in the current study based on the inclusion and exclusion criteria. A summary of the data extracted from the eligible articles are listed in Table 2.

\subsection{The Role of Resveratrol on Doxorubicin- Induced Cardiotoxicity}

3.2.1. Cell Viability and Survival Study. The in vitro findings revealed that the cell survival following treatment with doxorubicin was significantly less than the control group [32-43]. It was also fund that the doxorubicin-mediated cytotoxicity in cardiac cells had time- and dose-dependent manners. The results showed that there was a direct relation between the decreased cell count and posttreatment time/chemotherapy dosage [32, 34, 37, 39, 42]. However, the data obtained from the cell viability assay demonstrated that cotreatment of cardiac cells with resveratrol resulted in significant protective effects against doxorubicin-induced decrease in cell viability [32-43].

According to the in vivo results, the mortality of mice/rats treated with doxorubicin was significantly higher than that of the untreated group. The use of resveratrol significantly decreased doxorubicin-induced mortality $[38,44$,
45]. For instance, Angelis et al. reported that the mortality rate of $67 \%$ observed in doxorubicin-treated animals was reduced to $33 \%$ in the group cotreated with resveratrol and doxorubicin [38]. In other study by Cappetta et al., the mortality rate of $40 \%$ observed in doxorubicin-treated rats was declined to $12 \%$ in the resveratrol plus doxorubicin group [44]. Furthermore, it was found that resveratrol cotreatment delayed the doxorubicin-induced mortality in mice/rats to a much greater extent than the chemotherapy group alone [38, $44,45]$.

3.2.2. Body Weight, Heart Weight, and Ascites Changes. The results demonstrated that the body weight and heart weight of mice/rats were reduced in the doxorubicin groups than in the control groups [38, 43, 45-52]. Additionally, it was observed that the ratio of heart to the body weight as well as the ratio of heart weight to tibia length of animals was decreased following doxorubicin administration [43, 47, 48, 50]. Moreover, there was a significant accumulation of ascites in the doxorubicin-treated rats compared to the untreated rats. Of note, the survival rate in the rats with high ascites was significantly more than the other rats [38].

Coadministration of resveratrol and doxorubicin to the mice/rats increased the body weight, heart weight, ratio of heart to body weight, and ratio of heart weight to tibia length compared to the doxorubicin-treated groups alone [38, 43, $45-49,51,52]$. The increased ascites values of doxorubicintreated rats were significantly decreased by resveratrol cotreatment [38]. 
3.2.3. Changes Induced in Biochemical Markers. Some studies showed that the use of doxorubicin chemotherapy drug can induce the biochemical changes on heart cells/tissue (listed in Table 2). Briefly, it was observed that the reactive oxygen species (ROS), aspartate aminotransferase (AST), triglycerides, total cholesterol, 8-OHdG, malondialdehyde (MDA), myeloperoxidase (MPO), thiobarbituric acid reactive substances (TBARS), protein carbonyl, phosphor-p38, p53, p300, Bcl-2-associated X protein (BAX), cleaved caspase-3, cleaved poly (ADP-ribose) polymerase (PARP), atrial natriuretic peptide, fatty acid binding protein, creatine phosphokinase (CPK), creatine kinase-myocardial band (CK-MB), transforming growth factor beta 1 (TGF- $\beta 1$ ), E2F transcription factor 1 (E2F1), adenosine monophosphate- (AMP-) activated protein kinase (AMPK) $\alpha 2$, myocardial collagen I mRNA, collagen I/III, matrix metalloproteinase-2 (MMP-2), fibronectin, LC3-II, Beclin1 , nuclear factor of activated T cells 3 (NFAT3), mammalian target of rapamycin complex 1 (mTORC1), serum troponinI, toll-like receptor-4 (TLR-4), interleukin-6 (IL-6), tumor necrosis factor alpha (TNF- $\alpha$ ), and inducible nitric oxide synthase (iNOS) levels were significantly increased following doxorubicin administration than the control groups [35-38, 40-44, 46-61]. In contrast, the glutathione (GSH), catalase, superoxide dismutase (SOD), manganese SOD (MnSOD), glutathione peroxidase (GPx), alkaline phosphatase, GSH to glutathione disulfide (GSSG) ratio, total antioxidant capacity, B-cell lymphoma-extra large (Bcl-xL), B-cell lymphoma 2 (Bcl-2), heme oxygenase-1 (HO-1), phosphoAKT, insulin-like growth factor 1 receptor (IGF-1R), LC3II/LC3-I, phosphor-AMPK, NFAT5, vascular endothelial growth factor B (VEGF-B), and phospho-glycogen synthase kinase 3 beta (GSK-3 $\beta$ ) levels were significantly decreased in the doxorubicin-treated groups compared to the control groups [38, 40, 41, 43, 46, 48-51, 53-59, 61].

The resveratrol cotreatment alleviated doxorubicininduced biochemical changes on heart cells/tissue (for most of the cases) [35-38, 40-44, 46-61].

Some studies have reported conflicting findings on several biochemical markers (see Table 2). For instance, several studies demonstrated the elevated levels of lactate dehydrogenase (LDH) [41, 43, 46-48, 51, 53, 54, 61], creatine kinase $[48,58]$, and sirtuin 1 (SIRT1) $[39,47]$ following doxorubicin treatment alone, while other studies showed the decreased levels for these biomarkers [35, 38, 41, 44, 55, $58,59]$. Nevertheless, the combined treatment of resveratrol and doxorubicin showed a reverse manner on these biomarkers compared with chemotherapy groups alone [35, $38,41,43,44,46-48,51,53,54,58,59]$.

3.2.4. Histological Changes. A series of histological changes in cardiac tissue of animals have been reported following doxorubicin treatment, including congestion of blood vessels, cytoplasmic vacuolization, increments in edema, necrosis and inflammatory infiltration, hyalinization of muscle fiber, chromatin margination of nuclei and pyknotic nuclei, massive fragmentation and lysis of myofibrils, complete loss of cristae, interruption of $\mathrm{Z}$ lines, myocyte wavy degeneration, interstitial fibrosis, massive deposition of collagen, widely spaced deep acidophilic fibers, dense collagen fibers among thin fibers, massive interstitial hemorrhage and interfibrillar congestion, and so on (the other histological changes are represented in Table 2) [45, 46, 49, 51, 53-55, 62, 63].

According to the results of most studies, it was found that resveratrol coadministration can alleviate the doxorubicin-induced histological changes $[45,46,49,51$, $54,55,62,63]$.

\section{Discussion}

In the present systematic review, we aimed to assess the adverse effects of doxorubicin chemotherapeutic drug on the cardiac cells/tissue. The coadministration effects of resveratrol on this disorder were also investigated. Table 2 represents a summary of these findings. Furthermore, some of the important alterations on the cardiac cell following doxorubicin treatment as well as the effects of resveratrol on these changes are depicted in Figure 3.

Anthracyclines, as a class of chemotherapy drugs, can lead to chronic toxicity to the heart. The cardiotoxicity is more common in patients receiving doxorubicin, the most familiar anthracycline [64]. This chemotherapy agent has been widely applied for over forty years in case of different hematological and solid cancers [65]. In the cancerous cells, doxorubicin is capable of intercalation into DNA and disruption of DNA repair mediated by topoisomerase-II generation as well as production of free radicals and their damage to proteins, DNA, and cellular membranes [66]. Although doxorubicin has been standardized as an antitumoral drug, its potential life-threatening cardiomyopathy and congestive cardiac failure should be taken into consideration [67]. It has been shown that doxorubicin exerts toxic effects through oxidative stress, apoptosis, inflammation activities, etc. [68]. To mitigate the doxorubicin-induced cardiotoxicity, various studies have shown that the use of chemoprotective agents can provide acceptable results. In this regard, the combination treatment of doxorubicin with less toxic substances derived from plants, such as resveratrol, has received more attention in recent years.

The antitumoral activity of resveratrol has been reported in some cancers [69-72]. Resveratrol can also affect the expression of different genes [73, 74]. Additionally, it has been shown that resveratrol cotreatment not only can alleviate chemotherapy-induced adverse effects but can also decrease drug resistance (synergistic effect) $[75,76]$. Resveratrol exerts its chemoprotective effects via several mechanisms, including antioxidant, antiapoptotic, and antiinflammatory activities. In the following, the mechanistic effects of doxorubicin chemotherapeutic drug on the cardiac cellular pathway and also the chemoprotective effects of resveratrol and its underlying mechanisms on the doxorubicininduced cardiotoxicity are discussed.

4.1. Antioxidant Actions. Although oxygen molecules are necessary to survive aerobic cells, their forms of free radicals are dangerous to the cells [77]. On the other hand, the free radicals are commonly generated in the cells, but they are neutralized by several defense mechanisms [78]. In oxidative 


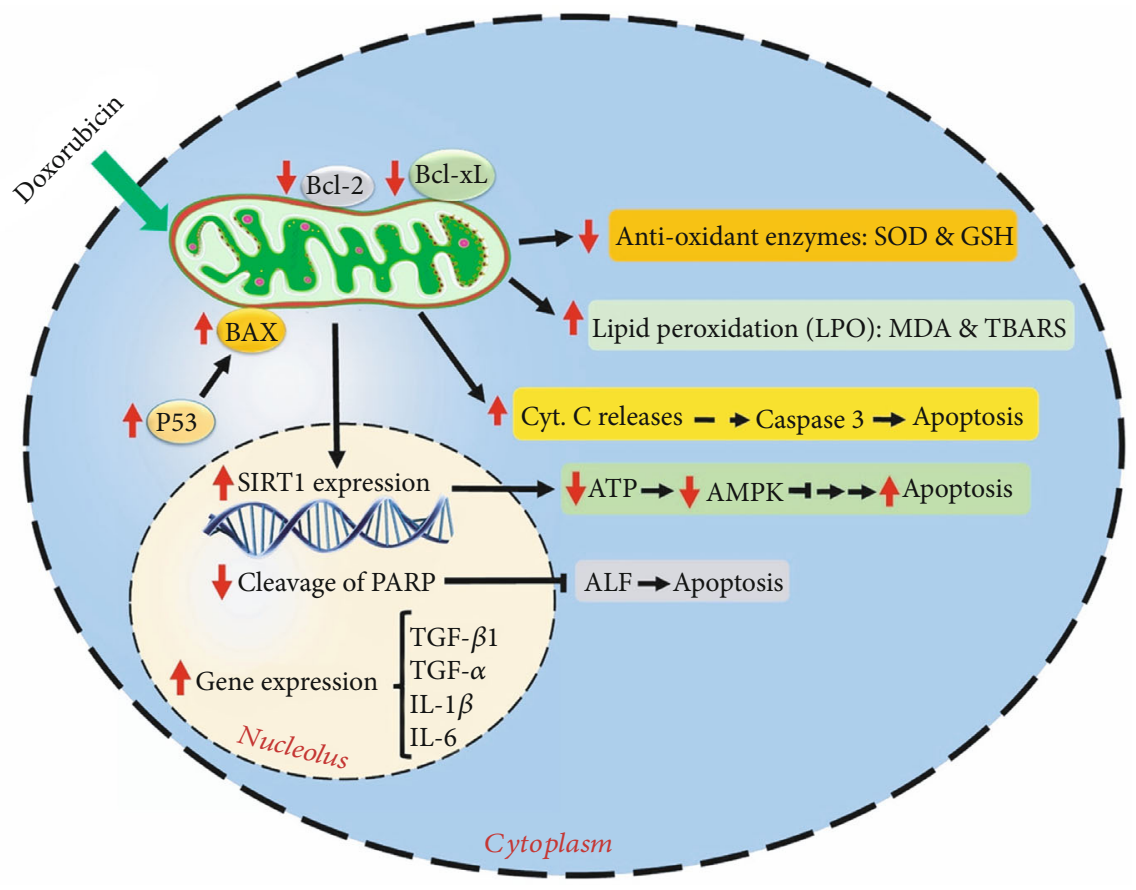

FIgURE 3: The molecular mechanisms of doxorubicin-induced cardiac cytotoxicity. This chemotherapy agent induces oxidative stress mostly via mitochondrial dysfunction. Doxorubicin increases free radicals via inhibition of SOD and GSH enzymes and also elevates LPO markers (MDA and TBARS). Moreover, doxorubicin increases apoptosis via reductions in BCL-2 and Bcl-xL, increments in BAX and p53 activations, increment in cytochrome $\mathrm{C}$ release, and elevation in caspase-3 level. Additionally, it induces apoptosis via reduction of PARP cleavage, as it leads to reductions in ATP and AMPK levels. Furthermore, doxorubicin increases the inflammatory mediators (such as IL6 , IL-1 $\beta$, TNF- $\alpha$, and TGF- $\beta 1$ ), leading to cell injury. Resveratrol, through an opposite pattern (antioxidant, antiapoptotic, and antiinflammatory activities), mitigates doxorubicin-induced cardiac cytotoxicity. $\uparrow$ : increased by doxorubicin; $\downarrow$ : decreased by doxorubicin; AMPK: AMP-activated protein kinase; AIF: apoptosis-inducing factor; Bcl-xL: B-cell lymphoma-extra large; Bcl-2: B-cell lymphoma 2; BAX: Bcl-2-associated X protein; GSH: glutathione; IL-6: interleukin-6; LPO: lipid peroxidation; MDA: malondialdehyde; SOD: superoxide dismutase; SIRT1: sirtuin 1; PARP: poly (ADP-ribose) polymerase; TBARS: thiobarbituric acid reactive substances; TGF- $\beta 1$ : transforming growth factor beta 1 ; TNF- $\alpha$ : tumor necrosis factor alpha.

stress conditions, such as chemotherapy, the amount of free radicals increases and an imbalance is created between the generated free radicals and the antioxidant defense system $[79,80]$. It has been reported that the use of doxorubicin increases the ROS level of cardiac cells, and subsequently, they are able to attack the cell macromolecules, leading to malfunction of the heart tissue $[35,38,50,59]$. Upon mitochondrial injury, the generation of free radicals in the cells elevates [81]; in this regard, doxorubicin through impairment of mitochondrial malfunction can increase the generated free radicals [35]. This chemotherapeutic agent also increases lipid peroxidation (LPO) markers of MDA and TBARS in the heart tissue, leading to the cell membrane devastation and malfunction [41, 46, 47, 49, 53-55, 58, 61]. Furthermore, it has been reported that doxorubicin administration declines GSH, catalase, GPx, and MnSOD levels $[41,46,49,50,53-55,58,61]$. Of note, $\mathrm{H}_{2} \mathrm{O}_{2}$ (as a nonradical ROS) through the activity of GPx enzyme and consuming GSH produces $2 \mathrm{H}_{2} \mathrm{O}$ [82]. The catalase enzyme also decomposes $\mathrm{H}_{2} \mathrm{O}_{2}$ to $\mathrm{H}_{2} \mathrm{O}$ and $\mathrm{O}_{2}$ [83]. Additionally, MnSOD is the mitochondrial SOD and acts as the primary line of defense system against oxidant stress [84]. These findings represent that doxorubicin impairs scavenging capacity of intracellular antioxidant enzymes.
According to the obtained results, it was found that resveratrol via the antioxidant actions could decrease doxorubicin-elevated ROS level of cardiac cells [35, 38, 50, 59]. This antioxidant agent is also able to polarize mitochondria, thereby inhibiting doxorubicin-induced ROS generation [35]. Furthermore, it has been reported that increased MnSOD activity following resveratrol cotreatment may play a main role in the reduction of ROS because the mitochondrion is the site of doxorubicin accumulation and the associated ROS generation [35, 50, 85]. Moreover, this herbal agent could upregulate GSH, catalase, and GPx expressions $[38,41,44,46,49,53,54,58,61]$ and downregulate MDA and TBARS levels in the cardiac cells $[41,46,47,49,53$, $54,58]$.

4.2. Antiapoptotic Actions. Apoptosis, as a physiological pathway, regulates cell death and controls the cell numbers. It is also needed to eliminate the harmed or transformed cells $[86,87]$. The oxidative stress conditions and massive DNA injury can lead to apoptosis $[88,89]$. There are some important mediators which are involved in the apoptosis process, including caspase enzymes, PARP, Bcl-2, p53, BAX, Bcl-xL, NFAT5, and ceramide [15, 90-99]. Evasion of apoptosis is one of the features of most cancerous cells, 
because any irregularity in this physiological process can induce cancer. Some chemotherapeutic agents are aimed at inducing apoptosis in cancerous cells [100]. It has been reported that doxorubicin administration increases apoptosis levels in the cardiac cells than the control groups [38$41,43,44,47,48,56,57,59,60,101]$. It is noteworthy that doxorubicin-induced apoptotic cardiomyocyte death (as a pathogenic mechanism in acute cardiotoxicity) [79, 102] and mitochondrial-dependent intrinsic apoptosis are considered as the main reasons for cardiac dysfunction [103]. Doxorubicin can downregulate Bcl-xL expression [51] and also upregulate BAX, cleaved caspase-3, and p53 expressions in the cardiac cells compared to the untreated groups [36$38,40-44,47-49,51,56,57,59,60]$. These findings indicate that the cells are moving towards apoptosis. Furthermore, doxorubicin can elevate PARP activity [36, 37, 42]. PARP is a nuclear enzyme and can regulate many cellular processes such as DNA repair, apoptosis, chromatin functions, and genomic stability $[15,104]$. Doxorubicin has also been implicated to trigger cardiac apoptosis through activation of c-Jun N-terminal kinase (JNK), p38, and p53 mitogenactivated protein kinase (MAPK) pathways [105]. MAPKs may also affect NFAT5 [106-109]. NFAT5 is a transcription factor which has a critical role in apoptosis [99]. It was shown that doxorubicin led to the increased level of NFAT5 in the cardiac cells [51].

Some studies have reported that resveratrol is able to induce apoptosis in different cancerous cells [110-115]. In addition to its apoptotic activities, this herbal agent through antiapoptotic effects can protect normal cells/tissues. According to the data represented in the current study, it was shown that combined treatment of resveratrol and doxorubicin declines the apoptosis level of cardiac cells compared to the doxorubicin-treated groups alone [38-41, 43, $44,47,48,56,57,59,60]$. Resveratrol combined to doxorubicin also upregulated Bcl-xL expression in the cardiac cells treated by doxorubicin [51], while this antiapoptotic agent downregulated BAX, cleaved caspase-3, p53, and PARP expressions [36-38, 40-44, 47-49, 51, 56, 57, 59, 60]. Furthermore, resveratrol cotreatment suppressed the increased levels of phospho-p38 and NFAT5 in the doxorubicintreated cardiac cells $[51,52,57,59]$.

4.3. Anti-Inflammatory Actions. The inflammatory process can occur following tissue injuries induced from various harmful stimuli, including chemotherapy, radiotherapy, microbial pathogen infection, and/or wounding [116-119]. The inflammation plays a vital role in tumor resistance and is responsible for the incidence of different adverse effects following chemotherapy [120]. It has been reported that doxorubicin can induce heart inflammation during cancer chemotherapy $[53,55]$. Moreover, doxorubicin-induced oxidative stress can affect LPO and activate lysosomal enzymes, leading to promote the inflammation in heart tissue [15]. It has also been reported that the doxorubicin administration upregulates proinflammatory mediators of TNF- $\alpha$, intercellular adhesion molecule-1 (ICAM-1), cyclooxygenase-2 (COX-2), TGF- $\beta$, nuclear factor-kappa B $(\mathrm{NF}-\kappa \mathrm{B}), \mathrm{MPO}$, IL- $1 \beta$, and IL- 6 levels in the cardiac cells
$[44,46,49,53,121]$. ICAM-1 is a surface protein that is able to infiltrate leucocytes to the damaged regions of heart tissue [122]. COX-2 is a proinflammatory enzyme, and it is overexpressed at the inflammatory site of cancer [123]. TGF- $\beta$, as a profibrogenic cytokine, mediates several aspects of the fibrotic process. In this regard, it induces fibroblast proliferation and transformation to myofibroblasts which leads to the deposition of collagen and extracellular matrix protein $[124,125]$. TGF- $\beta$ is also able to modulate cell proliferation, differentiation, apoptosis, and migration [126]. Furthermore, doxorubicin could decline $\mathrm{HO}-1$ level in the cardiac cells [48]. HO-1 is a nuclear factor-erythroid factor 2related factor 2- (Nrf2-) regulated gene that has a vital role in the prevention of vascular inflammation [127].

The anti-inflammatory effects of resveratrol on various normal/tumoral tissues have been reported [22, 128-132]. Resveratrol, through its anti-inflammatory activities, can protect the normal cells and also decrease the resistance of cancer cells to chemotherapy drugs. The findings represented in the current systematic review demonstrated that resveratrol cotreatment alleviates the doxorubicin-induced cardiac inflammation. In this regard, it was found that combined treatment of resveratrol and doxorubicin declines the elevated levels of TNF- $\alpha$, TGF- $\beta 1$, MPO, and IL- 6 and also increased HO-1 level in the heart tissue of the doxorubicin-treated rats [44, 46, 49, 53, 57]. Moreover, the histological findings showed that doxorubicin-induced inflammation is mitigated by resveratrol administration $[46,49,53,55,58]$.

\section{Perspective of Future Research}

Doxorubicin, as a chemotherapy drug, is commonly used for the treatment of various cancers. Nevertheless, the clinical use of doxorubicin may be restricted because of its adverse effects on the normal cells/tissues, especially cardiotoxicity. Researchers reported that the use of chemoprotective agents, such as resveratrol, can alleviate the doxorubicin-induced cardiotoxicity. This herbal agent exerts its chemoprotective effects through several main mechanisms of antioxidant, antiapoptosis, and anti-inflammatory. In addition to its chemoprotective effect, resveratrol can sensitize cancer cells to chemotherapy drugs (chemosensitizer effects) [133-136]. Despite its remarkable protective effects, unfavorable pharmacokinetics/pharmacodynamics profile of resveratrol such as poor bioavailability has restricted its applications [137, 138]. To solve this problem, some studies have introduced novel derivatives and analogues for this chemoprotective agent [139-147]. Additionally, it has been proposed that nanostrategies for delivery of resveratrol can overcome these limitations [20, 148-151].

It should be mentioned that the data represented in the current systematic review are based on in vitro and in vivo models. Therefore, suggesting the use of resveratrol as a chemoprotector agent combined to doxorubicin in cancer patients requires further studies, because sometimes results are different between the in vitro and in vivo models and clinical studies. 


\section{Limitations}

Some limitations should be addressed. Firstly, significant heterogeneity was encountered perhaps because of different regimens, doses, duration, center settings, populations enrolled, and so on, calling for cautious interpretation of the findings. Secondly, many of the studies suffer from significant sources of bias. Thirdly, the effect in many occasions was evaluated by very few studies; therefore, the evidence to support it is low.

\section{Conclusion}

The findings showed that doxorubicin chemotherapeutic agent can induce the biochemical and histological changes on the cardiac cells/tissue. However, using resveratrol alleviates the doxorubicin-induced adverse effects on the cardiac cells/tissue. Mechanically, resveratrol exerts its chemoprotective effects through several main mechanisms of antioxidant, antiapoptosis, and anti-inflammatory.

\section{Data Availability}

The data used to support the findings of this study are available from the corresponding author upon request.

\section{Conflicts of Interest}

The authors declare that they have no conflict of interest.

\section{Authors' Contributions}

L-F $\mathrm{H}$ and H-R L performed the literature search, wrote the manuscript, and drafted the figures. X-M L and K-T J gave the idea, edited the manuscript, and supervised the whole study. All authors read and approved the manuscript. LiFeng $\mathrm{Hu}$ and Huan-Rong Lan contributed equally to this work.

\section{Acknowledgments}

This work was supported by Zhejiang Provincial Science and Technology Projects (grant no. LGD19H160001 to JKT).

\section{References}

[1] K. Mortezaee, A. Narmani, M. Salehi et al., "Synergic effects of nanoparticles-mediated hyperthermia in radiotherapy/chemotherapy of cancer," Life Sciences, vol. 269, p. 119020, 2021.

[2] S. Sheikholeslami, S. Khodaverdian, M. Dorri-Giv et al., "The radioprotective effects of alpha-lipoic acid on radiotherapyinduced toxicities: a systematic review," International Immunopharmacology, vol. 96, p. 107741, 2021.

[3] R. L. Siegel, K. D. Miller, and A. Jemal, "Cancer statistics, 2015,” CA: A Cancer Journal for Clinicians, vol. 65, no. 1, pp. 5-29, 2015.

[4] F. Bray, J. Ferlay, I. Soerjomataram, R. L. Siegel, L. A. Torre, and A. Jemal, "Global cancer statistics 2018: GLOBOCAN estimates of incidence and mortality worldwide for 36 can- cers in 185 countries," CA: A Cancer Journal for Clinicians, vol. 68, no. 6, pp. 394-424, 2018.

[5] H. Sung, J. Ferlay, R. L. Siegel et al., "Global cancer statistics 2020: GLOBOCAN estimates of incidence and mortality worldwide for 36 cancers in 185 countries," CA: A Cancer Journal for Clinicians, vol. 71, no. 3, pp. 209-249, 2021.

[6] M. T. Bahreyni Toossi, S. Soleymanifard, B. Farhood, S. Mohebbi, and D. Davenport, "Assessment of accuracy of out-of-field dose calculations by TiGRT treatment planning system in radiotherapy," Journal of Cancer Research and Therapeutics, vol. 14, no. 3, pp. 634-639, 2018.

[7] N. Abdi Goushbolagh, R. Abedi Firouzjah, K. Ebrahimnejad Gorji et al., "Estimation of radiation dose-reduction factor for cerium oxide nanoparticles in MRC-5 human lung fibroblastic cells and MCF-7 breast-cancer cells," Artificial Cells, Nanomedicine, and Biotechnology, vol. 46, sup3, pp. S1215S1225, 2018.

[8] N. Abdi Goushbolagh, M. Keshavarz, M. H. Zare, M. H. Bahreyni-Toosi, M. Kargar, and B. Farhood, "Photosensitizer effects of MWCNTs-COOH particles on CT26 fibroblastic cells exposed to laser irradiation," Artificial Cells, Nanomedicine, and Biotechnology, vol. 47, no. 1, pp. 1326-1334, 2019.

[9] S. Sheikholeslami, T. Aryafar, R. Abedi-Firouzjah et al., "The role of melatonin on radiation-induced pneumonitis and lung fibrosis: a systematic review," Life Sciences, vol. 281, p. 119721, 2021.

[10] H. Haghi-Aminjan, B. Farhood, M. Rahimifard et al., "The protective role of melatonin in chemotherapy-induced nephrotoxicity: a systematic review of non-clinical studies," Expert Opinion on Drug Metabolism \& Toxicology, vol. 14, no. 9, pp. 937-950, 2018.

[11] H. Haghi-Aminjan, M. H. Asghari, B. Farhood, M. Rahimifard, N. Hashemi Goradel, and M. Abdollahi, "The role of melatonin on chemotherapy-induced reproductive toxicity," The Journal of Pharmacy and Pharmacology, vol. 70, no. 3, pp. 291-306, 2018.

[12] Y. Octavia, C. G. Tocchetti, K. L. Gabrielson, S. Janssens, H. J. Crijns, and A. L. Moens, "Doxorubicin-induced cardiomyopathy: from molecular mechanisms to therapeutic strategies," Journal of Molecular and Cellular Cardiology, vol. 52, no. 6, pp. 1213-1225, 2012.

[13] P. K. Singal and N. Iliskovic, "Doxorubicin-induced cardiomyopathy," The New England Journal of Medicine, vol. 339, no. 13, pp. 900-905, 1998.

[14] K. Chatterjee, J. Zhang, N. Honbo, and J. S. Karliner, "Doxorubicin cardiomyopathy," Cardiology, vol. 115, no. 2, pp. 155-162, 2010.

[15] M. Najafi, M. R. Hooshangi Shayesteh, K. Mortezaee, B. Farhood, and H. Haghi-Aminjan, "The role of melatonin on doxorubicin-induced cardiotoxicity: a systematic review," Life Sciences, vol. 241, p. 117173, 2020.

[16] B. Salehi, A. P. Mishra, M. Nigam et al., "Resveratrol: a double-edged sword in health benefits," Biomedicines, vol. 6 , no. 3, p. 91, 2018.

[17] A. Rezaeyan, P. Amini, H. Fallah, and M. Najafi, "Radiation protection and mitigation by natural antioxidants and flavonoids: implications to radiotherapy and radiation disasters," Current Molecular Pharmacology, vol. 11, no. 4, pp. 285304, 2018.

[18] J. Gusman, H. Malonne, and G. Atassi, "A reappraisal of the potential chemopreventive and chemotherapeutic properties 
of resveratrol," Carcinogenesis, vol. 22, no. 8, pp. 1111-1117, 2001.

[19] S. Pervaiz and A. L. Holme, "Resveratrol: its biologic targets and functional activity," Antioxidants \& Redox Signaling, vol. 11, no. 11, pp. 2851-2897, 2009.

[20] Z. Ahmadi, R. Mohammadinejad, and M. Ashrafizadeh, "Drug delivery systems for resveratrol, a non-flavonoid polyphenol: emerging evidence in last decades," Journal of Drug Delivery Science and Technology, vol. 51, pp. 591-604, 2019.

[21] C. A. de la Lastra and I. Villegas, "Resveratrol as an antioxidant and pro-oxidant agent: mechanisms and clinical implications," Biochemical Society Transactions, vol. 35, no. 5, pp. 1156-1160, 2007.

[22] K. Mortezaee, M. Najafi, B. Farhood, A. Ahmadi, D. Shabeeb, and A. E. Musa, "Resveratrol as an adjuvant for normal tissues protection and tumor sensitization," Current Cancer Drug Targets, vol. 20, no. 2, pp. 130-145, 2020.

[23] T. Kisková and M. Kassayová, "Resveratrol action on lipid metabolism in cancer," International Journal of Molecular Sciences, vol. 20, no. 11, 2019.

[24] M. Honari, R. Shafabakhsh, R. J. Reiter, H. Mirzaei, and Z. Asemi, "Resveratrol is a promising agent for colorectal cancer prevention and treatment: focus on molecular mechanisms," Cancer Cell International, vol. 19, no. 1, p. 180, 2019.

[25] J. H. Ko, G. Sethi, J. Y. Um et al., "The role of resveratrol in cancer therapy," International Journal of Molecular Sciences, vol. 18, no. 12, p. 2589, 2017.

[26] Q. Xiao, W. Zhu, W. Feng et al., "A review of resveratrol as a potent chemoprotective and synergistic agent in cancer chemotherapy," Frontiers in Pharmacology, vol. 9, p. 1534, 2018.

[27] E. M. Varoni, A. F. Lo Faro, J. Sharifi-Rad, and M. Iriti, “Anticancer molecular mechanisms of resveratrol," Frontiers in Nutrition, vol. 3, p. 8, 2016.

[28] P. R. Van Ginkel, D. Sareen, L. Subramanian et al., "Resveratrol inhibits tumor growth of human neuroblastoma and mediates apoptosis by directly targeting mitochondria," Clinical Cancer Research: An Official Journal of the American Association for Cancer Research, vol. 13, no. 17, pp. 51625169, 2007.

[29] K. Koide, S. Osman, A. L. Garner et al., "The use of 3,5,4'-triO-acetylresveratrol as a potential pro-drug for resveratrol protects mice from $\gamma$-irradiation-induced death," ACS Medicinal Chemistry Letters, vol. 2, no. 4, pp. 270-274, 2011.

[30] S. Agah, A. Akbari, E. Sadeghi et al., "Resveratrol supplementation and acute pancreatitis: a comprehensive review," Biomedicine \& Pharmacotherapy, vol. 137, article 111268, 2021.

[31] D. Moher, A. Liberati, J. Tetzlaff, and D. G. Altman, "Preferred reporting items for systematic reviews and meta-analyses: the PRISMA statement," Annals of Internal Medicine, vol. 151, no. 4, pp. 264-269, 2009, w64.

[32] Z. Cao and Y. Li, "Potent induction of cellular antioxidants and phase 2 enzymes by resveratrol in cardiomyocytes: protection against oxidative and electrophilic injury," European Journal of Pharmacology, vol. 489, no. 1-2, pp. 39-48, 2004.

[33] Y. A. Rezk, S. S. Balulad, R. S. Keller, and J. A. Bennett, "Use of resveratrol to improve the effectiveness of cisplatin and doxorubicin: study in human gynecologic cancer cell lines and in rodent heart," American Journal of Obstetrics and Gynecology, vol. 194, no. 5, pp. e23-e26, 2006.

[34] B. B. Yu, X. Z. Han, and H. X. Lou, "Oligomers of resveratrol and ferulic acid prepared by peroxidase-catalyzed oxidation and their protective effects on cardiac injury," Journal of Agricultural and Food Chemistry, vol. 55, no. 19, pp. 7753-7757, 2007.

[35] E. D. Danz, J. Skramsted, N. Henry, J. A. Bennett, and R. S. Keller, "Resveratrol prevents doxorubicin cardiotoxicity through mitochondrial stabilization and the Sirt1 pathway," Free Radical Biology \& Medicine, vol. 46, no. 12, pp. 15891597, 2009.

[36] X. Xu, K. Chen, S. Kobayashi, D. Timm, and Q. Liang, "Resveratrol attenuates doxorubicin-induced cardiomyocyte death via inhibition of p70 S6 kinase 1-mediated autophagy," The Journal of Pharmacology and Experimental Therapeutics, vol. 341, no. 1, pp. 183-195, 2012.

[37] W. Yang, I. J. Park, H. Yun et al., “AMP-activated Protein Kinase $\alpha 2$ and E2F1 Transcription Factor Mediate Doxorubicin-induced Cytotoxicity by Forming a Positive Signal Loop in Mouse Embryonic Fibroblasts and Noncarcinoma Cells*," The Journal of Biological Chemistry, vol. 289, no. 8, pp. 4839-4852, 2014.

[38] A. De Angelis, E. Piegari, D. Cappetta et al., "SIRT1 activation rescues doxorubicin-induced loss of functional competence of human cardiac progenitor cells," International Journal of Cardiology, vol. 189, pp. 30-44, 2015.

[39] Y. U. Lou, Z. Wang, Y. I. Xu et al., "Resveratrol prevents doxorubicin-induced cardiotoxicity in $\mathrm{H} 9 \mathrm{c} 2$ cells through the inhibition of endoplasmic reticulum stress and the activation of the Sirt1 pathway," International Journal of Molecular Medicine, vol. 36, no. 3, pp. 873-880, 2015.

[40] M. H. Liu, X. L. Lin, D. M. Guo et al., "Resveratrol protects cardiomyocytes from doxorubicin-induced apoptosis through the AMPK/P53 pathway," Molecular Medicine Reports, vol. 13, no. 2, pp. 1281-1286, 2016.

[41] M. H. Liu, J. Shan, J. Li, Y. Zhang, and X. L. Lin, "Resveratrol inhibits doxorubicin-induced cardiotoxicity via sirtuin 1 activation in H9c2 cardiomyocytes," Experimental and Therapeutic Medicine, vol. 12, no. 2, pp. 1113-1118, 2016.

[42] L. Yang, C. Luo, C. Chen, X. Wang, W. Shi, and J. Liu, “Alltrans retinoic acid protects against doxorubicin-induced cardiotoxicity by activating the ERK2 signalling pathway," British Journal of Pharmacology, vol. 173, no. 2, pp. 357-371, 2016.

[43] W. Tian, L. Yang, Y. Liu et al., "Resveratrol attenuates doxorubicin-induced cardiotoxicity in rats by up- regulation of vascular endothelial growth factor B," The Journal of Nutritional Biochemistry, vol. 79, p. 108132, 2020.

[44] D. Cappetta, G. Esposito, E. Piegari et al., "SIRT1 activation attenuates diastolic dysfunction by reducing cardiac fibrosis in a model of anthracycline cardiomyopathy," International Journal of Cardiology, vol. 205, pp. 99-110, 2016.

[45] L. Zhang, K. Zhu, H. Zeng et al., "Resveratrol solid lipid nanoparticles to trigger credible inhibition of doxorubicin cardiotoxicity," International Journal of Nanomedicine, vol. Volume 14, pp. 6061-6071, 2019.

[46] E. Tatlidede, Ö. Şehirli, A. Velioğlu-Öğünç et al., "Resveratrol treatment protects against doxorubicin-induced cardiotoxicity by alleviating oxidative damage," Free Radical Research, vol. 43, no. 3, pp. 195-205, 2009.

[47] C. Zhang, Y. Feng, S. Qu et al., "Resveratrol attenuates doxorubicin-induced cardiomyocyte apoptosis in mice through SIRT1-mediated deacetylation of p53," Cardiovascular Research, vol. 90, no. 3, pp. 538-545, 2011. 
[48] J. Gu, Z. P. Song, D. M. Gui, W. Hu, Y. G. Chen, and D. D. Zhang, "Resveratrol attenuates doxorubicin-induced cardiomyocyte apoptosis in lymphoma nude mice by heme oxygenase-1 induction," Cardiovascular Toxicology, vol. 12, no. 4, pp. 341-349, 2012.

[49] M. H. Arafa, N. S. Mohammad, H. H. Atteia, and H. R. AbdElaziz, "Protective effect of resveratrol against doxorubicininduced cardiac toxicity and fibrosis in male experimental rats," Journal of Physiology and Biochemistry, vol. 70, no. 3, pp. 701-711, 2014.

[50] V. W. Dolinsky, K. J. Rogan, M. M. Sung et al., "Both aerobic exercise and resveratrol supplementation attenuate doxorubicin-induced cardiac injury in mice," American Journal of Physiology-Endocrinology and Metabolism, vol. 305, no. 2, pp. E243-E253, 2013.

[51] H. S. Shoukry, H. I. Ammar, L. A. Rashed et al., "Prophylactic supplementation of resveratrol is more effective than its therapeutic use against doxorubicin induced cardiotoxicity," PLoS One, vol. 12, no. 7, article e0181535, 2017.

[52] N. Matsumura, B. N. Zordoky, I. M. Robertson et al., "Coadministration of resveratrol with doxorubicin in young mice attenuates detrimental late-occurring cardiovascular changes," Cardiovascular Research, vol. 114, no. 10, pp. 1350-1359, 2018.

[53] A. M. Alanazi, L. Fadda, A. Alhusaini, R. Ahmad, I. H. Hasan, and A. M. Mahmoud, "Liposomal resveratrol and/or carvedilol attenuate doxorubicin-induced cardiotoxicity by modulating inflammation, oxidative stress and S100A1 in rats," Antioxidants, vol. 9, no. 2, 2020.

[54] S. E. Al-Harthi, O. M. Alarabi, W. S. Ramadan et al., "Amelioration of doxorubicin-induced cardiotoxicity by resveratrol," Molecular Medicine Reports, vol. 10, no. 3, pp. 1455-1460, 2014.

[55] J. Dudka, R. Gieroba, A. Korga et al., "Different effects of resveratrol on dose-related doxorubicin-induced heart and liver toxicity," Evidence-Based Complementary and Alternative Medicine, vol. 2012, Article ID 606183, 10 pages, 2012.

[56] J. Gu, Y. Q. Fan, H. L. Zhang et al., "Resveratrol suppresses doxorubicin-induced cardiotoxicity by disrupting E2F1 mediated autophagy inhibition and apoptosis promotion," Biochemical Pharmacology, vol. 150, pp. 202-213, 2018.

[57] J. Gu, W. Hu, Z. P. Song, Y. G. Chen, D. D. Zhang, and C. Q. Wang, "Resveratrol-induced autophagy promotes survival and attenuates doxorubicin-induced cardiotoxicity," International Immunopharmacology, vol. 32, pp. 1-7, 2016.

[58] K. Mukherjee, M. Venkatesh, P. Venkatesh, B. P. Saha, and P. K. Mukherjee, "Effect of soy phosphatidyl choline on the bioavailability and nutritional health benefits of resveratrol," Foodservice Research International, vol. 44, no. 4, pp. 10881093, 2011.

[59] Y. Ruan, C. Dong, J. Patel et al., "SIRT1 suppresses doxorubicin-induced cardiotoxicity by regulating the oxidative stress and p38MAPK pathways," Cellular Physiology and Biochemistry, vol. 35, no. 3, pp. 1116-1124, 2015.

[60] T. K. Sin, B. T. Tam, B. Y. Yung et al., "Resveratrol protects against doxorubicin-induced cardiotoxicity in aged hearts through the SIRT1-USP7 axis," The Journal of Physiology, vol. 593, no. 8, pp. 1887-1899, 2015.

[61] H. L. Wang, J. P. Gao, Y. L. Han et al., "Comparative studies of polydatin and resveratrol on mutual transformation and antioxidative effect in vivo," Phytomedicine, vol. 22, no. 5, pp. 553-559, 2015.
[62] A. M. Osman, S. E. Al-Harthi, A. A. OM et al., "Chemosensetizing and cardioprotective effects of resveratrol in doxorubicin- treated animals," Cancer Cell International, vol. 13, p. 52, 2013.

[63] F. A. Pınarlı, N. N. Turan, F. Güçlü Pınarlı et al., "Resveratrol and adipose-derived mesenchymal stem cells are effective in the prevention and treatment of doxorubicin cardiotoxicity in rats," Pediatric Hematology and Oncology, vol. 30, no. 3, pp. 226-238, 2013.

[64] P. Altieri, C. Barisione, E. Lazzarini et al., "Testosterone antagonizes doxorubicin-induced senescence of cardiomyocytes," Journal of the American Heart Association, vol. 5, no. 1, 2016.

[65] V. S. Warpe, V. R. Mali, S. Arulmozhi, S. L. Bodhankar, and K. R. Mahadik, "Cardioprotective effect of ellagic acid on doxorubicin induced cardiotoxicity in Wistar rats," Journal of Acute Medicine, vol. 5, no. 1, pp. 1-8, 2015.

[66] D. A. Gewirtz, "A critical evaluation of the mechanisms of action proposed for the antitumor effects of the anthracycline antibiotics Adriamycin and daunorubicin," Biochemical Pharmacology, vol. 57, no. 7, pp. 727-741, 1999.

[67] Y. QuanJun, Y. GenJin, W. LiLi et al., "Protective effects of dexrazoxane against doxorubicin-induced cardiotoxicity: a metabolomic study," PLoS One, vol. 12, no. 1, article e0169567, 2017.

[68] A. Pugazhendhi, T. Edison, B. K. Velmurugan, J. A. Jacob, and I. Karuppusamy, "Toxicity of doxorubicin (Dox) to different experimental organ systems," Life Sciences, vol. 200, pp. 26-30, 2018.

[69] S. Chottanapund, M. B. Van Duursen, P. Navasumrit et al., "Anti-aromatase effect of resveratrol and melatonin on hormonal positive breast cancer cells co-cultured with breast adipose fibroblasts," Toxicology in Vitro, vol. 28, no. 7, pp. 12151221, 2014.

[70] J. J. Junco, A. Mancha, G. Malik et al., "Resveratrol and Pglycoprotein inhibitors enhance the anti-skin cancer effects of ursolic acid," Molecular Cancer Research, vol. 11, no. 12, pp. 1521-1529, 2013.

[71] Z. Wang, W. Li, X. Meng, and B. Jia, "Resveratrol induces gastric cancer cell apoptosis via reactive oxygen species, but independent of sirtuin1," Clinical and Experimental Pharmacology \& Physiology, vol. 39, no. 3, pp. 227-232, 2012.

[72] F. Amiri, A. H. Zarnani, H. Zand, F. Koohdani, M. Jeddi-Tehrani, and M. Vafa, "Synergistic anti-proliferative effect of resveratrol and etoposide on human hepatocellular and colon cancer cell lines," European Journal of Pharmacology, vol. 718, no. 1-3, pp. 34-40, 2013.

[73] S. Abdollahi, A. Salehi-Abargouei, M. Tabatabaie et al., "The effect of resveratrol supplementation on the expression levels of factors associated with cellular senescence and sCD163/sTWEAK ratio in patients with type 2 diabetes mellitus: study protocol for a double-blind controlled randomised clinical trial," BMJ Open, vol. 9, no. 7, article e026337, 2019.

[74] O. Toupchian, S. Abdollahi, A. Salehi-Abargouei et al., "The effects of resveratrol supplementation on $\operatorname{PPAR} \alpha, \mathrm{p} 16, \mathrm{p} 53$, p21 gene expressions, and sCD163/sTWEAK ratio in patients with type 2 diabetes mellitus: a double-blind controlled randomized trial," Phytotherapy Research, vol. 35, no. 6, pp. 3205-3213, 2021.

[75] Y. Z. Chen, Z. D. Li, F. Gao, Y. Zhang, H. Sun, and P. P. Li, "Effects of combined Chinese drugs and chemotherapy in 
treating advanced non-small cell lung cancer," Chinese Journal of Integrative Medicine, vol. 15, no. 6, pp. 415-419, 2009.

[76] L. Huang, S. Zhang, J. Zhou, and X. Li, "Effect of resveratrol on drug resistance in colon cancer chemotherapy," RSC Advances, vol. 9, no. 5, pp. 2572-2580, 2019.

[77] H. Haghi-Aminjan, M. H. Asghari, M. H. Goharbari, and M. Abdollahi, "A systematic review on potential mechanisms of minocycline in kidney diseases," Pharmacological Reports, vol. 69, no. 4, pp. 602-609, 2017.

[78] N. Nobakht-Haghighi, M. Rahimifard, M. Baeeri et al., "Regulation of aging and oxidative stress pathways in aged pancreatic islets using alpha-lipoic acid," Molecular and Cellular Biochemistry, vol. 449, no. 1-2, pp. 267-276, 2018.

[79] P. B. Narayanaswamy, M. Hodjat, H. Haller, I. Dumler, and Y. Kiyan, "Loss of urokinase receptor sensitizes cells to DNA damage and delays DNA repair," PLoS One, vol. 9, no. 7, article e101529, 2014.

[80] S. Momtaz, M. Baeeri, M. Rahimifard, H. Haghi-Aminjan, S. Hassani, and M. Abdollahi, "Manipulation of molecular pathways and senescence hallmarks by natural compounds in fibroblast cells," Journal of Cellular Biochemistry, vol. 120, no. 4, pp. 6209-6222, 2019.

[81] K. Niaz, F. I. Hassan, F. Mabqool et al., "Effect of styrene exposure on plasma parameters, molecular mechanisms and gene expression in rat model islet cells," Environmental Toxicology and Pharmacology, vol. 54, pp. 62-73, 2017.

[82] B. J. Day, "Catalase and glutathione peroxidase mimics," Biochemical Pharmacology, vol. 77, no. 3, pp. 285-296, 2009.

[83] B. Shrestha, J. M. Reed, P. T. Starks et al., "Evolution of a major drug metabolizing enzyme defect in the domestic cat and other felidae: phylogenetic timing and the role of hypercarnivory," PLoS One, vol. 6, no. 3, article e18046, 2011.

[84] M. Assem, J. R. Teyssier, M. Benderitter et al., "Pattern of superoxide dismutase enzymatic activity and RNA changes in rat heart ventricles after myocardial infarction," The American Journal of Pathology, vol. 151, no. 2, pp. 549-555, 1997.

[85] E. Salvatorelli, S. Guarnieri, P. Menna et al., "Defective oneor two-electron reduction of the anticancer anthracycline epirubicin in human heart. Relative importance of vesicular sequestration and impaired efficiency of electron addition," The Journal of Biological Chemistry, vol. 281, no. 16, pp. 10990-11001, 2006.

[86] M. Najafi, K. Mortezaee, M. Rahimifard, B. Farhood, and H. Haghi-Aminjan, "The role of curcumin/curcuminoids during gastric cancer chemotherapy: a systematic review of non-clinical study," Life Sciences, vol. 257, p. 118051, 2020.

[87] S. Bohlooli, N. Jafari, and S. Jahed, "Cytotoxic effect of freezedried extract of Ecballium elaterium fruit on gastric adenocarcinoma (AGS) and esophageal squamous cell carcinoma (KYSE30) cell lines," Journal of Gastrointestinal Cancer, vol. 43, no. 4, pp. 579-583, 2012.

[88] K. Z. Oben, B. W. Gachuki, S. S. Alhakeem et al., "Radiation induced apoptosis of murine bone marrow cells is independent of early growth response 1 (EGR1)," PLoS One, vol. 12, no. 1, article e0169767, 2017.

[89] E. A. Komarova, R. V. Kondratov, K. Wang et al., "Dual effect of $\mathrm{p} 53$ on radiation sensitivity in vivo: $\mathrm{p} 53$ promotes hematopoietic injury, but protects from gastro-intestinal syndrome in mice," Oncogene, vol. 23, no. 19, pp. 3265-3271, 2004.

[90] K. Mortezaee, M. Najafi, B. Farhood et al., "Modulation of apoptosis by melatonin for improving cancer treatment effi- ciency: an updated review," Life Sciences, vol. 228, pp. 228241, 2019.

[91] N. Sogwagwa, G. Davison, S. Khan, and W. Solomon, "P9. Correlation of radiation induced apoptosis with Bax and Bcl-2 protein expression," Physica Medica: European Journal of Medical Physics, vol. 32, p. 163, 2016.

[92] S. Huerta, X. Gao, S. Dineen, P. Kapur, D. Saha, and J. Meyer, "Role of p53, Bax, p21, and DNA-PKcs in radiation sensitivity of HCT-116 cells and xenografts," Surgery, vol. 154, no. 2, pp. 143-151, 2013.

[93] L. R. Werner, S. Huang, D. M. Francis et al., "Small molecule inhibition of MDM2-p53 interaction augments radiation response in human tumors," Molecular Cancer Therapeutics, vol. 14, no. 9, pp. 1994-2003, 2015.

[94] O. Csuka, E. Remenár, K. Koronczay, Z. Doleschall, and G. Németh, "Predictive value of p53, Bcl2 and bax in the radiotherapy of head and neck cancer," Pathology Oncology Research, vol. 3, no. 3, pp. 204-210, 1997.

[95] K. Maebayashi, N. Mitsuhashi, T. Takahashi, H. Sakurai, and H. Niibe, "p53 mutation decreased radiosensitivity in rat yolk sac tumor cell lines," International Journal of Radiation Oncology • Biology • Physics, vol. 44, no. 3, pp. 677-682, 1999.

[96] T. Sugihara, H. Murano, M. Nakamura, K. Ichinohe, and K. Tanaka, "p53-mediated gene activation in mice at high doses of chronic low-dose-rate $\gamma$ radiation," Radiation Research, vol. 175, no. 3, pp. 328-335, 2011.

[97] E. A. Punnoose, J. D. Leverson, F. Peale et al., "Expression profile of BCL-2, BCL-XL, and MCL-1 predicts pharmacological response to the BCL-2 selective antagonist venetoclax in multiple myeloma models," Molecular Cancer Therapeutics, vol. 15, no. 5, pp. 1132-1144, 2016.

[98] A. Haimovitz-Friedman, R. N. Kolesnick, and Z. Fuks, "Ceramide signaling in apoptosis," British Medical Bulletin, vol. 53, no. 3, pp. 539-553, 1997.

[99] H. Kim, W. S. Yoo, J. H. Jung et al., “Alpha-lipoic acid ameliorates radiation-induced lacrimal gland injury through NFAT5-dependent signaling," International journal of molecular sciences, vol. 20, no. 22, 2019.

[100] C. Krakstad and M. Chekenya, "Survival signalling and apoptosis resistance in glioblastomas: opportunities for targeted therapeutics," Molecular Cancer, vol. 9, p. 135, 2010.

[101] C. Bastiaan, P. Dierickx, S. Crnko et al., "Neonatal rat cardiomyocytes as an in vitro model for circadian rhythms in the heart," Journal of Molecular and Cellular Cardiology, vol. 112, pp. 58-63, 2017.

[102] S. Wang, Y. Wang, Z. Zhang, Q. Liu, and J. Gu, "Cardioprotective effects of fibroblast growth factor 21 against doxorubicin-induced toxicity via the SIRT1/LKB1/AMPK pathway," Cell Death \& Disease, vol. 8, no. 8, article e3018, 2017.

[103] L. B. Priya, R. Baskaran, C. Y. Huang, and V. V. Padma, "Neferine ameliorates cardiomyoblast apoptosis induced by doxorubicin: possible role in modulating NADPH oxidase/ROS-mediated $\mathrm{NF} \kappa \mathrm{B}$ redox signaling cascade," Scientific Reports, vol. 7, no. 1, p. 12283, 2017.

[104] Z. Herceg and Z. Q. Wang, "Functions of poly(ADP-ribose) polymerase (PARP) in DNA repair, genomic integrity and cell death," Mutation Research, vol. 477, no. 1-2, pp. 97110, 2001.

[105] J. Das, J. Ghosh, P. Manna, and P. C. Sil, "Taurine suppresses doxorubicin-triggered oxidative stress and cardiac apoptosis 
in rat via up-regulation of PI3-K/Akt and inhibition of p53, p38-JNK," Biochemical Pharmacology, vol. 81, no. 7, pp. 891-909, 2011.

[106] J. H. Lee, M. Kim, Y. S. Im, W. Choi, S. H. Byeon, and H. K. Lee, "NFAT5 induction and its role in hyperosmolar stressed human limbal epithelial cells," Investigative Ophthalmology \& Visual Science, vol. 49, no. 5, pp. 1827-1835, 2008.

[107] N. Lee, D. Kim, and W. U. Kim, "Role of NFAT5 in the immune system and pathogenesis of autoimmune diseases," Frontiers in Immunology, vol. 10, p. 270, 2019.

[108] K. Takeda, A. Matsuzawa, H. Nishitoh, and H. Ichijo, "Roles of MAPKKK ASK1 in stress-induced cell death," Cell Structure and Function, vol. 28, no. 1, pp. 23-29, 2003.

[109] L. Chang and M. Karin, "Mammalian MAP kinase signalling cascades," Nature, vol. 410, no. 6824, pp. 37-40, 2001.

[110] H. Y. Lin, H. Y. Tang, T. Keating et al., "Resveratrol is proapoptotic and thyroid hormone is anti-apoptotic in glioma cells: both actions are integrin and ERK mediated," Carcinogenesis, vol. 29, no. 1, pp. 62-69, 2008.

[111] H. Y. Lin, A. I. Shih, F. B. Davis et al., "Resveratrol induced serine phosphorylation of p53 causes apoptosis in a mutant p53 prostate cancer cell line," The Journal of urology, vol. 168, no. 2, pp. 748-755, 2002.

[112] X. Wu, Y. Xu, B. Zhu, Q. Liu, Q. Yao, and G. Zhao, "Resveratrol induces apoptosis in SGC-7901 gastric cancer cells," Oncology Letters, vol. 16, no. 3, pp. 2949-2956, 2018.

[113] S. Zhang, H. J. Cao, F. B. Davis, H. Y. Tang, P. J. Davis, and H. Y. Lin, "Oestrogen inhibits resveratrol-induced posttranslational modification of p53 and apoptosis in breast cancer cells," British Journal of Cancer, vol. 91, no. 1, pp. 178185, 2004.

[114] H. Y. Lin, M. Sun, H. Y. Tang et al., "Resveratrol causes COX2- and p53-dependent apoptosis in head and neck squamous cell cancer cells," Journal of Cellular Biochemistry, vol. 104, no. 6, pp. 2131-2142, 2008.

[115] Y. Liu, L. Tong, Y. Luo, X. Li, G. Chen, and Y. Wang, "Resveratrol inhibits the proliferation and induces the apoptosis in ovarian cancer cells via inhibiting glycolysis and targeting AMPK/mTOR signaling pathway," Journal of Cellular Biochemistry, vol. 119, no. 7, pp. 6162-6172, 2018.

[116] L. Ramachandran and C. K. K. Nair, "Therapeutic potentials of silver nanoparticle complex of $\alpha$-lipoic acid," Nanomaterials and Nanotechnology, vol. 1, p. 14, 2011.

[117] D. Vyas, G. Laput, and A. K. Vyas, "Chemotherapy-enhanced inflammation may lead to the failure of therapy and metastasis," OncoTargets and Therapy, vol. 7, pp. 10151023, 2014.

[118] H. Haghi Aminjan, S. R. Abtahi, E. Hazrati, M. Chamanara, M. Jalili, and B. Paknejad, "Targeting of oxidative stress and inflammation through ROS/NF-kappaB pathway in phosphine-induced hepatotoxicity mitigation," Life Sciences, vol. 232, p. 116607, 2019.

[119] M. R. H. Shayesteh, H. Haghi-Aminjan, M. J. Mousavi, S. Momtaz, and M. Abdollahi, "The protective mechanism of cannabidiol in cardiac injury: a systematic review of nonclinical studies," Current Pharmaceutical Design, vol. 25, no. 22, pp. 2499-2507, 2019.

[120] B. Farhood, K. Mortezaee, N. H. Goradel et al., "Curcumin as an anti-inflammatory agent: implications to radiotherapy and chemotherapy," Journal of Cellular Physiology, vol. 234, no. 5, pp. 5728-5740, 2019.
[121] M. M. Aziz, M. A. Abd El Fattah, K. A. Ahmed, and H. M. Sayed, "Protective effects of olmesartan and l-carnitine on doxorubicin-induced cardiotoxicity in rats," Canadian Journal of Physiology and Pharmacology, vol. 98, no. 4, pp. 183193, 2020.

[122] F. Olivares-Silva, R. Landaeta, P. Aránguiz et al., "Heparan sulfate potentiates leukocyte adhesion on cardiac fibroblast by enhancing Vcam-1 and Icam-1 expression," Biochimica et Biophysica Acta, Molecular Basis of Disease, vol. 1864, no. 3, pp. 831-842, 2018.

[123] V. Raj, A. S. Bhadauria, A. K. Singh et al., "Novel 1,3,4-thiadiazoles inhibit colorectal cancer via blockade of IL-6/COX2 mediated JAK2/STAT3 signals as evidenced through databased mathematical modeling," Cytokine, vol. 118, pp. 144$159,2019$.

[124] M. Martin, J. Lefaix, and S. Delanian, "TGF-beta1 and radiation fibrosis: a master switch and a specific therapeutic target?," International Journal of Radiation Oncology • Biology - Physics, vol. 47, no. 2, pp. 277-290, 2000.

[125] D. Kim, Y. Choi, Y. Ki, K. Cho, Y. Choi, and W. Kim, “Topically applied melatonin ameliorates radiation-induced skin fibrosis in mice," International Journal of Radiation Research, vol. 17, no. 4, pp. 617-624, 2019.

[126] S. Gencer, N. Oleinik, J. Kim et al., “TGF- $\beta$ receptor I/II trafficking and signaling at primary cilia are inhibited by ceramide to attenuate cell migration and tumor metastasis," Science Signaling, vol. 10, no. 502, 2017.

[127] J. A. Araujo, M. Zhang, and F. Yin, "Heme oxygenase-1, oxidation, inflammation, and atherosclerosis," Frontiers in Pharmacology, vol. 3, p. 119, 2012.

[128] L. E. Donnelly, R. Newton, G. E. Kennedy et al., “Anti-inflammatory effects of resveratrol in lung epithelial cells: molecular mechanisms," American Journal of Physiology-Lung Cellular and Molecular Physiology, vol. 287, no. 4, pp. L774-L783, 2004.

[129] S. Bereswill, M. Muñoz, A. Fischer et al., "Anti-inflammatory effects of resveratrol, curcumin and simvastatin in acute small intestinal inflammation," PLoS One, vol. 5, no. 12, article e15099, 2010.

[130] R. Azmoonfar, P. Amini, R. Yahyapour et al., "Mitigation of radiation-induced pneumonitis and lung fibrosis using alpha-lipoic acid and resveratrol," Anti-Inflammatory \& Anti-Allergy Agents in Medicinal Chemistry, vol. 19, no. 2, pp. 149-157, 2020.

[131] C. Buhrmann, M. Yazdi, B. Popper et al., "Resveratrol chemosensitizes TNF- $\beta$-induced survival of 5-FU-treated colorectal cancer cells," Nutrients, vol. 10, no. 7, p. 888, 2018.

[132] R. S. Said, E. M. Mantawy, and E. El-Demerdash, "Mechanistic perspective of protective effects of resveratrol against cisplatin-induced ovarian injury in rats: emphasis on antiinflammatory and anti-apoptotic effects," Naunyn-Schmiedeberg's Archives of Pharmacology, vol. 392, no. 10, pp. 12251238, 2019.

[133] C. Buhrmann, P. Shayan, P. Kraehe, B. Popper, A. Goel, and M. Shakibaei, "Resveratrol induces chemosensitization to 5fluorouracil through up-regulation of intercellular junctions, epithelial-to-mesenchymal transition and apoptosis in colorectal cancer," Biochemical Pharmacology, vol. 98, no. 1, pp. 51-68, 2015.

[134] Y. J. Lee, G. J. Lee, S. S. Yi et al., "Cisplatin and resveratrol induce apoptosis and autophagy following oxidative stress in malignant mesothelioma cells," Food and Chemical 
Toxicology: An International Journal Published for the British Industrial Biological Research Association, vol. 97, pp. 96107, 2016.

[135] X. P. Shi, S. Miao, Y. Wu et al., "Resveratrol sensitizes tamoxifen in antiestrogen-resistant breast cancer cells with epithelial-mesenchymal transition features," International Journal of Molecular Sciences, vol. 14, no. 8, pp. 1565515668, 2013.

[136] W. Zhang, H. Jiang, Y. Chen, and F. Ren, "Resveratrol chemosensitizes Adriamycin-resistant breast cancer cells by modulating miR-122-5p," Journal of Cellular Biochemistry, vol. 120, no. 9, pp. 16283-16292, 2019.

[137] T. Walle, F. Hsieh, M. H. DeLegge, J. E. Oatis Jr., and U. K. Walle, "High absorption but very low bioavailability of oral resveratrol in humans," Drug Metabolism and Disposition: The Biological Fate of Chemicals, vol. 32, no. 12, pp. 13771382, 2004.

[138] K. Bove, D. W. Lincoln, and M. F. Tsan, "Effect of resveratrol on growth of $4 \mathrm{~T} 1$ breast cancer cells in vitro and in vivo," Biochemical and Biophysical Research Communications, vol. 291, no. 4, pp. 1001-1005, 2002.

[139] C. M. Remsberg, J. A. Yáñez, Y. Ohgami, K. R. Vega-Villa, A. M. Rimando, and N. M. Davies, "Pharmacometrics of pterostilbene: preclinical pharmacokinetics and metabolism, anticancer, antiinflammatory, antioxidant and analgesic activity," Phytotherapy Research, vol. 22, no. 2, pp. 169-179, 2008.

[140] T. T. Wang, N. W. Schoene, Y. S. Kim, C. S. Mizuno, and A. M. Rimando, "Differential effects of resveratrol and its naturally occurring methylether analogs on cell cycle and apoptosis in human androgen-responsive LNCaP cancer cells," Molecular Nutrition \& Food Research, vol. 54, no. 3, pp. 335-344, 2010.

[141] D. Alex, E. C. Leong, Z. J. Zhang et al., "Resveratrol derivative, trans-3, 5, 4'-trimethoxystilbene, exerts antiangiogenic and vascular-disrupting effects in zebrafish through the downregulation of VEGFR2 and cell-cycle modulation," Journal of Cellular Biochemistry, vol. 109, no. 2, pp. 339-346, 2010.

[142] Z. Horvath, S. Marihart-Fazekas, P. Saiko et al., "Novel resveratrol derivatives induce apoptosis and cause cell cycle arrest in prostate cancer cell lines," Anticancer Research, vol. 27, no. 5a, pp. 3459-3464, 2007.

[143] L. A. Stivala, M. Savio, F. Carafoli et al., "Specific structural determinants are responsible for the antioxidant activity and the cell cycle effects of resveratrol," The Journal of Biological Chemistry, vol. 276, no. 25, pp. 22586-22594, 2001.

[144] M. Larrosa, F. A. Tomás-Barberán, and J. C. Espín, “Grape polyphenol resveratrol and the related molecule 4hydroxystilbene induce growth inhibition, apoptosis, Sphase arrest, and upregulation of cyclins A, E, and B1 in human SK-Mel-28 melanoma cells," Journal of Agricultural and Food Chemistry, vol. 51, no. 16, pp. 4576-4584, 2003.

[145] M. Savio, T. Coppa, L. Bianchi et al., "The resveratrol analogue $4,4^{\prime}$-dihydroxy-trans-stilbene inhibits cell proliferation with higher efficiency but different mechanism from resveratrol," The International Journal of Biochemistry \& Cell Biology, vol. 41, no. 12, pp. 2493-2502, 2009.

[146] Y. Kimura, M. Sumiyoshi, and K. Baba, “Antitumor activities of synthetic and natural stilbenes through antiangiogenic action," Cancer Science, vol. 99, no. 10, pp. 2083-2096, 2008.
[147] N. Handler, G. Brunhofer, C. Studenik et al., "'Bridged' stilbene derivatives as selective cyclooxygenase-1 inhibitors," Bioorganic \& Medicinal Chemistry, vol. 15, no. 18, pp. 6109-6118, 2007.

[148] V. Vergaro, Y. M. Lvov, and S. Leporatti, "Halloysite clay nanotubes for resveratrol delivery to cancer cells," Macromolecular Bioscience, vol. 12, no. 9, pp. 1265-1271, 2012.

[149] M. Wang, Y. Liu, X. Zhang et al., "Gold nanoshell coated thermo-pH dual responsive liposomes for resveratrol delivery and chemo-photothermal synergistic cancer therapy," Journal of Materials Chemistry B, vol. 5, no. 11, pp. 2161-2171, 2017.

[150] W. Wang, L. Zhang, T. Chen et al., "Anticancer effects of resveratrol-loaded solid lipid nanoparticles on human breast cancer cells," Molecules, vol. 22, no. 11, 2017.

[151] S. Karthikeyan, N. Rajendra Prasad, A. Ganamani, and E. Balamurugan, "Anticancer activity of resveratrol-loaded gelatin nanoparticles on NCI-H460 non-small cell lung cancer cells," Biomedicine \& Preventive Nutrition, vol. 3, no. 1, pp. 64-73, 2013. 